\title{
Hygroscopicity of organic surrogate compounds from biomass burning and their effect on the efflorescence of ammonium sulfate in mixed aerosol particles
}

\author{
Ting Lei ${ }^{1,2}$, Andreas Zuend ${ }^{4}$, Yafang Cheng ${ }^{2,3}$, Hang $\mathrm{Su}^{2,3}$, Weigang Wang ${ }^{1}$, and Maofa Ge ${ }^{1}$ \\ ${ }^{1}$ State Key Laboratory for Structural Chemistry of Unstable and Stable Species, CAS Research/Education Center for \\ Excellence in Molecular Sciences, Institute of Chemistry, Chinese Academy of Sciences, Beijing, 100190, China \\ ${ }^{2}$ Multiphase Department, Max Planck Institute for Chemistry, Mainz 55128, Germany \\ ${ }^{3}$ Institute for Environmental and Climate Research, Jinan University, Guangzhou, China \\ ${ }^{4}$ Department of Atmospheric and Oceanic Sciences, McGill University, Montreal, Quebec, Canada
}

Correspondence: Maofa Ge (gemaofa@iccas.ac.cn)

Received: 13 June 2017 - Discussion started: 20 June 2017

Revised: 29 November 2017 - Accepted: 2 December 2017 - Published: 26 January 2018

\begin{abstract}
Hygroscopic growth factors of organic surrogate compounds representing biomass burning and mixed organic-inorganic aerosol particles exhibit variability during dehydration experiments depending on their chemical composition, which we observed using a hygroscopicity tandem differential mobility analyzer (HTDMA). We observed that levoglucosan and humic acid aerosol particles release water upon dehumidification in the range from 90 to $5 \%$ relative humidity (RH). However, 4-Hydroxybenzoic acid aerosol particles remain in the solid state upon dehumidification and exhibit a small shrinking in size at higher $\mathrm{RH}$ compared to the dry size. For example, the measured growth factor of 4-hyroxybenzoic acid aerosol particles is $\sim 0.96$ at $90 \%$ $\mathrm{RH}$. The measurements were accompanied by RH-dependent thermodynamic equilibrium calculations using the Aerosol Inorganic-Organic Mixtures Functional groups Activity Coefficients (AIOMFAC) model and Extended Aerosol Inorganics Model (E-AIM), the Zdanovskii-Stokes-Robinson (ZSR) relation, and a fitted hygroscopicity expression. We observed several effects of organic components on the hygroscopicity behavior of mixtures containing ammonium sulfate (AS) in relation to the different mass fractions of organic compounds: (1) a shift of efflorescence relative humidity (ERH) of ammonium sulfate to higher RH due to the presence of $25 \mathrm{wt} \%$ levoglucosan in the mixture. (2) There is a distinct efflorescence transition at $25 \% \mathrm{RH}$ for mixtures consisting of $25 \mathrm{wt} \%$ of 4-hydroxybenzoic acid compared to the ERH at $35 \%$ for organic-free AS particles.
\end{abstract}

(3) There is indication for a liquid-to-solid phase transition of 4-hydroxybenzoic acid in the mixed particles during dehydration. (4) A humic acid component shows no significant effect on the efflorescence of AS in mixed aerosol particles. In addition, consideration of a composition-dependent degree of dissolution of crystallization AS (solid-liquid equilibrium) in the AIOMFAC and E-AIM models leads to a relatively good agreement between models and observed growth factors, as well as ERH of AS in the mixed system. The use of the ZSR relation leads to good agreement with measured diameter growth factors of aerosol particles containing humic acid and ammonium sulfate. Lastly, two distinct mixtures of organic surrogate compounds, including levoglucosan, 4hydroxybenzoic acid, and humic acid, were used to represent the average water-soluble organic carbon (WSOC) fractions observed during the wet and dry seasons in the central Amazon Basin. A comparison of the organic fraction's hygroscopicity parameter for the simple mixtures, e.g., $\kappa \approx 0.12$ to 0.15 for the wet-season mixture in the 90 to $40 \% \mathrm{RH}$ range, shows good agreement with field data for the wet season in the Amazon Basin (WSOC $\kappa \approx 0.14 \pm 0.06$ at $90 \% \mathrm{RH}$ ). This suggests that laboratory-generated mixtures containing organic surrogate compounds and ammonium sulfate can be used to mimic, in a simplified manner, the chemical composition of ambient aerosols from the Amazon Basin for the purpose of RH-dependent hygroscopicity studies. 


\section{Introduction}

It is well established that biomass burning, as an important source of atmospheric aerosol particles, has a wide range of climate effects that can be classified into direct radiative effects through light-absorbing carbon aerosol particles and indirect effects by impact on cloud condensation nuclei $(\mathrm{CCN})$ and cloud microphysics (Andreae and Gelencsér, 2006; Moosmüller et al., 2009; Hecobian et al., 2010; Rizzo et al., 2011; Rose et al., 2011; Cheng et al., 2012; Engelhart et al., 2012; Lack et al., 2012; Jacobson, 2014; Liu et al., 2014; Saleh et al., 2013, 2014). Atmospheric lightabsorbing particles that arise from biomass burning play an important role as a driver of global warming (Favez et al., 2009; Hegg et al., 2010; Lack et al., 2012; Laborde et al., 2013; Srinivas and Sarin, 2013). According to the IPCC report (Boucher and David, 2013; IPCC, 2013), the climate forcing of black carbon aerosol particles may rival that of methane, with a present-day global warming effect of up to $0.3-0.4^{\circ} \mathrm{C}$ (Wang et al., 2014). Also, certain types of aerosol particles emitted by biomass burning, when immersed into cloud droplets, absorb solar radiation and facilitate water evaporation and cloud dispersion, which indicates an additional indirect aerosol effect that counteracts the cooling effect of cloud droplets nucleated by aerosols (Powelson et al., 2014). Therefore, a better understanding of the influence of aerosol particles from biomass burning on cloud formation, precipitation, and Earth's radiative budget is required to comprehend biomass burning aerosol properties and behavior.

The understanding of the aerosol-cloud-climate impact of a vast range of organic compounds derived from biomass burning, however, is rather limited due to the complexity of biomass burning emissions, gas- and aerosol-phase processing, and the restricted availability of field measurements (Pratt et al., 2011; Lei et al., 2014; Paglione et al., 2014; Srinivas and Sarin, 2014; Zhong and Jang, 2014; Arnold et al., 2015; Lawson et al., 2015; Gilman et al., 2015). Moreover, biomass burning particles are often mixtures of watersoluble organic carbon, black carbon, varying amounts of inorganic components, and water-insoluble inclusions, such as mineral dust or poorly soluble organics (Väkevä et al., 2002; Sadezky et al., 2005; Saarnio et al., 2010). An appreciable number of organic compounds affect the physicochemical properties of aerosols, such as hygroscopicity, liquidsolid and liquid-liquid phase transitions, and chemical reactivity in liquid phases and/or on particle surfaces (Shiraiwa et al., 2013). For example, equilibrium between the variable environmental water vapor mixing ratio and aerosol particles may lead to substantial changes in particle size and chemical composition, all of which can influence light absorption and scattering (Seinfeld and Pandis, 2006; Zhang et al., 2016). Transitions between solid and liquid (aqueous) phases that are dependent on relative humidity $(\mathrm{RH})$ are also important in determining optical properties (Martin et al., 2013; Wang et al., 2010; Kim et al., 2016; Wu et al., Den- jean et al., 2015, 2016; Hodas et al., 2015; Atkinson et al., 2015). Studies have shown that water-soluble organic matter from biomass burning (approximately $70 \%$ of total organic matter) can significantly suppress, enhance, or have no effect on the deliquescence (e.g., the RH at which deliquescence occurs at a certain temperature, the DRH) and efflorescence processes (e.g., the efflorescence RH, ERH) of present inorganic electrolytes. The effect depends predominantly on the type of organics, mass fraction of organics relative to inorganics, and particle size (Zawadowicz et al., 2015; Hodas et al., 2015; Gupta et al., 2015). Whole particles, individual phases within particles, or specific chemical compounds can undergo a range of phase transitions including crystallization-efflorescence, dissolution-deliquescence, and liquid-liquid phase separation as the $\mathrm{RH}$ varies in the atmosphere. A number of laboratory studies have focused on liquid-liquid phase separations within particles consisting of inorganic and organic fractions (Svenningsson et al., 2006; Carrico et al., 2008; Dusek et al., 2011; Hodas et al., 2015). For example, studies about liquid-liquid separation occurring in mixed organic-inorganic aerosols were performed by Song et al. (2012a, b) and You et al. (2013) using Raman and optical microscopy, establishing that liquidliquid phase separation typically occurs in mixed organics + ammonium sulfate (AS) particles with an average elemental oxygen-to-carbon $(\mathrm{O}: \mathrm{C})$ ratio of the organic fraction of less than 0.6 and in some cases for $0.6<\mathrm{O}: \mathrm{C}<0.8$. You et al. (2013) further found that for a $\mathrm{O}: \mathrm{C}$ ratio between 0.5 and 0.8 , the occurrence of liquid-liquid phase separation at a moderate to high $\mathrm{RH}$ depends on the types of inorganic salts present (i.e., the effective strength of the salting-out effect), e.g., $\left(\mathrm{NH}_{4}\right)_{2} \mathrm{SO}_{4} \geq \mathrm{NH}_{4} \mathrm{HSO}_{4} \geq \mathrm{NaCl} \geq \mathrm{NH}_{4} \mathrm{NO}_{3}$. Recently, the effect of a potential size-dependent morphology and dependence of the phase separation mechanism on the organic / inorganic mass ratio in mixed aerosol was studied for mixtures of poly(ethylene glycol)-400 + ammonium sulfate using cryogenic-transmission electron microscopy (Altaf et al., 2016). Therefore, many independent studies suggest that the occurrence of solid-liquid and/or liquidliquid phase separations, as well as related (temperaturedependent) RH levels of phase transitions (DRH, ERH, and onset of RH of liquid-liquid phase separation, SRH), depend on the relative amounts of organic and inorganic aerosol components and their nonideal mixing behavior.

The expected physical state and morphology of aerosol particles containing mixtures of a wide range of organic and inorganic salts and acids can, in principle, be predicted by a selection of specialized thermodynamic equilibrium models. Such models include the Extended Aerosol Inorganic Model (E-AIM) (Clegg et al., 1998; Clegg and Seinfeld, 2006; available online: http://www.aim.env.uea.ac.uk/ aim/aim.php), the Aerosol Diameter Dependent Equilibrium Model (ADDEM) (Topping et al., 2005), the universal quasichemical functional group activity coefficients (UNIFAC) method (Fredenslund et al., 1975; Hansen et al., 1991), and 
Table 1. Substances and their physical properties used in this work.

\begin{tabular}{|c|c|c|c|c|c|c|}
\hline Chemical compound & $\begin{array}{l}\text { Chemical } \\
\text { formula }\end{array}$ & $\begin{array}{r}\text { Molar } \\
\text { mass } \\
\left(\mathrm{g} \mathrm{mol}^{-1}\right)\end{array}$ & $\begin{array}{r}\text { Density in solid } \\
\text { or liquid state } \\
\left(\mathrm{g} \mathrm{cm}^{-3}\right)\end{array}$ & $\begin{array}{r}\text { Solubility } \\
\left(\mathrm{g}\left(100 \mathrm{~cm}^{3} \mathrm{H}_{2} \mathrm{O}\right)^{-1}\right)\end{array}$ & $\begin{array}{r}\text { Solution } \\
\text { surface } \\
\text { tension } \\
\left(\mathrm{J} \mathrm{m}^{-2}\right)\end{array}$ & Manufacturer \\
\hline $\begin{array}{l}\text { Ammonium } \\
\text { sulfate }\end{array}$ & $\left(\mathrm{NH}_{4}\right)_{2} \mathrm{SO}_{4}$ & 132.140 & $\begin{array}{l}1.770^{\mathrm{a}} \text { (solid), } \\
1.550^{\mathrm{a}} \text { (liquid) }\end{array}$ & $\begin{array}{r}74.400 \\
\text { (at } 20^{\circ} \text { ) }\end{array}$ & $\begin{array}{r}0.072 \\
\left(0.001-10 \mathrm{mg} \mathrm{mL}^{-1}\right)\end{array}$ & $\begin{array}{l}\text { Alfa Aesar, } \\
99.95 \%\end{array}$ \\
\hline Levoglucosan & $\mathrm{C}_{6} \mathrm{H}_{10} \mathrm{O}_{5}$ & 126.100 & $\begin{array}{r}1.618^{\mathrm{b}} \text { (solid) } \\
1.512^{\mathrm{b}} \text { (liquid) }\end{array}$ & & $\begin{array}{r}0.073^{\mathrm{c}} \\
\left(0.01-10 \mathrm{mg} \mathrm{mL}^{-1}\right)\end{array}$ & $\begin{array}{l}\text { Aldrich, } \\
99 \%\end{array}$ \\
\hline $\begin{array}{l}\text { 4-Hydroxybenzoic } \\
\text { acid }\end{array}$ & $\mathrm{C}_{7} \mathrm{H}_{6} \mathrm{O}_{3}$ & 138.100 & $\begin{array}{r}1.460 \text { (solid) } \\
1.372^{\mathrm{d}} \text { (liquid) }\end{array}$ & $\begin{array}{r}0.675 \\
\left(\text { at } 25^{\circ}\right)\end{array}$ & $\begin{array}{r}0.070^{\mathrm{e}} \\
\left(>10 \mathrm{mg} \mathrm{mL}^{-1}\right)\end{array}$ & $\begin{array}{l}\text { Alfa Aesar, } \\
99.99 \%\end{array}$ \\
\hline Humic acid & & NA & $0.800^{\mathrm{f}}$ (solid) & NA & $0.073^{\mathrm{g}}$ & Aldrich, $99 \%$ \\
\hline
\end{tabular}

${ }^{a}$ Clegg and Wexler (2011a). ${ }^{b}$ Lienhard et al. (2012). ${ }^{c}$ Tuckermann and Cammenga (2004) at 293 K. ${ }^{d}$ Jedelsky et al. (2000). ${ }^{\text {e }}$ Kiss et al. (2005). ${ }^{\mathrm{f}}$ Yates III and Wandruszka (1999). ${ }^{\mathrm{g}}$ Mikhailov et al. (2008).

the Aerosol Inorganic-Organic Mixtures Functional groups Activity Coefficients (AIOMFAC) model (Zuend et al., 2008, 2011, 2012). These models have all been used to predict atmospheric aerosol thermodynamic equilibrium for a variety of inorganic and organic systems, yet not all of them can be used to compute nonideal mixing in organic-inorganic systems. AIOMFAC has been used to predict the distribution of components in multiple phases in a range of mixed organicinorganic systems and demonstrated its broad applicability in predicting liquid-liquid phase separation in such mixtures (Zuend et al., 2010; Song et al., 2012; Zuend and Seinfeld, 2012; Shiraiwa et al., 2013; Renbaum-Woff et al., 2016; Rastak et al., 2017).

Several previous experimental studies using the hygroscopicity tandem differential mobility analyzer (HTDMA) technique (e.g., Zardini et al., 2008; Lei et al., 2014) show that the deliquescence of inorganic compounds is affected by the presence of organic components, which manifests itself in a shift in the DRH of a salt compared to the corresponding organic-free system. For instance, a clear shift of AS DRH was observed in the case of the levoglucosan + ammonium sulfate system (Lei et al., 2014). Here we focus on investigating the morphology, hygroscopicity, and phase transitions of relevant organic compounds found in biomass burning aerosol during the dehydration-dehumidification process. Moreover, we study how the presence of organic compounds affects the water loss behavior of mixed organic-inorganic aerosols with AS in the supersaturated state as well as after efflorescence of AS. In addition, we compare the measured hygroscopicity behavior of mixed aerosol particles with predictions from the Zdanovskii-Stokes-Robinson (ZSR) mixing rule, the E-AIM model, and the AIOMFAC model.

\section{Methods}

\subsection{Aerosol system}

The three organic compounds levoglucosan, 4hydroxybenzoic acid, and humic acid were used as surrogates for the rich class of water-soluble organic components in biomass burning aerosols. The influence of the distinct chemical structure of these compounds was studied with regard to the water uptake and evaporation of the pure organic compounds as well as for mixed particles containing organics and AS. Furthermore, a comparison with field data from the Amazon Basin was preformed to quantify the ability of mixtures of these three organic compounds to mimic the hygroscopic behavior of complex ambient organic particles originating from biomass burning emissions. Here we focus on the characterization of hygroscopic growth factors (HGFs) as well as solid-liquid and liquid-liquid phase transitions during the dehumidification conditions. The chemical substances and their physical properties are characterized in Table 1. All of the experimental solutions were prepared by dissolving in Milli-Q water (resistivity $\geq 18.2 \mathrm{M} \Omega$ ) and the experiments were conducted at room temperature $(\sim 298 \mathrm{~K})$. The chemical compositions of biomass burning model mixtures are introduced in Table 2 .

\subsection{Instrument design}

Figure 1 shows a schematic of the HTDMA instrument; more detailed information about this instrument's setup, calibration and evaluation is described elsewhere (Lei et al., 2014; Jing et al., 2016; Liu et al., 2016). Briefly, polydisperse sub-micrometer aerosol particles are generated by atomizing (MSP 1500, MSP) a 0.05 weight \% aqueous solution consisting of different mass fractions of inorganic and organic components, assuming that the composition of the aerosol particles formed is initially the same as that of the 
Table 2. The chemical composition of biomass-burning model mixtures studied given as mass percentages (wt \%). See Sect. 3.3 for more information.

\begin{tabular}{lllll}
\hline Mixture name & Levoglucosan & 4-Hydroxybenzoic acid & Humic acid & Ammonium sulfate \\
\hline Mix-bio-dry & $87.2 \%$ & $9.2 \%$ & $1.5 \%$ & $2.1 \%$ \\
Mix-bio-wet & $68.0 \%$ & $26.0 \%$ & $3.0 \%$ & $3.0 \%$ \\
\hline
\end{tabular}

solution used in the atomizer. Aerosol particles from an atomizer are routed though homemade silica diffusion dryers and then pass through a Nafion gas dryer (Perma Pure Inc., USA). After aerosol particles were dried to below $5 \% \mathrm{RH}$ (RH set point 1, RH1), they are directed to the impactor; those aerosols with a diameter less than $1 \mu \mathrm{m}$ are allowed to pass and subsequently pass through a ${ }^{85} \mathrm{Kr}$ electric charger to reach a near-Boltzmann distribution of charges (Liu et al., 1985). After charging, the aerosol particles enter the first differential mobility analyzer (DMA1) at a sheath flow-toaerosol flow ratio of $4: 0.3$. The sheath flow is circulated by the diaphragm pump in the first loop DMA1 system, and its $\mathrm{RH}$ is kept constant at below $5 \% \mathrm{RH}$. The resulting monodisperse particle population, selected within uncertainty by the DMA1, is then exposed to high-RH conditions during which the aerosol flow is humidified to $98 \% \mathrm{RH}$ by mixing water through a Nafion membrane humidifier at $30^{\circ} \mathrm{C}$. After passing through a saturator (Perma Pure Inc., USA), the aerosols are dried to a target $\mathrm{RH}$ level (RH2) through a series of two single-Nafion tubes (Perma Pure Inc., USA) with RH2 set to a value in the range of 90 to $5 \% \mathrm{RH}$. Here, a pulse width modulator circuit is used to regulate the sheath flow on the basis of a proportional integral derivative system. When the second Nafion membranes allow for regulating the sheath flow to a desired RH and for controlled flow into the sample stream until the RH2 setting value is equal to the excess RH of sheath flow value (RH3), the mobility diameter of the dehumidified aerosols at target RH is measured with the second DMA (DMA2, a scanning DMA) coupled with a condensation particle counter (model 1500, MSP). In addition, the residence time between the humidifier and DMA2 is around $5 \mathrm{~s}$, which is estimated to be sufficient for aerosols to grow or shrink to equilibrium size at a certain RH set point. Also, due to recirculation of the sheath flow and the pre-humidification of the aerosol flow, the sheath flow and aerosol sample flow are enabled to rapidly reach the same $\mathrm{RH}$.

\subsection{Theory and modeling methods}

Models were applied to explore the extent to which measured HGFs, particle phase states, and phase compositions under subsaturation conditions can be predicted using thermodynamic equilibrium models. For the AS-containing system studies, the current thermodynamic equilibrium predictions account for a crystalline AS phase with solid-liquid equilibria prior to the complete deliquescence of AS under hydration conditions. Similarly, the crystallization point fol-

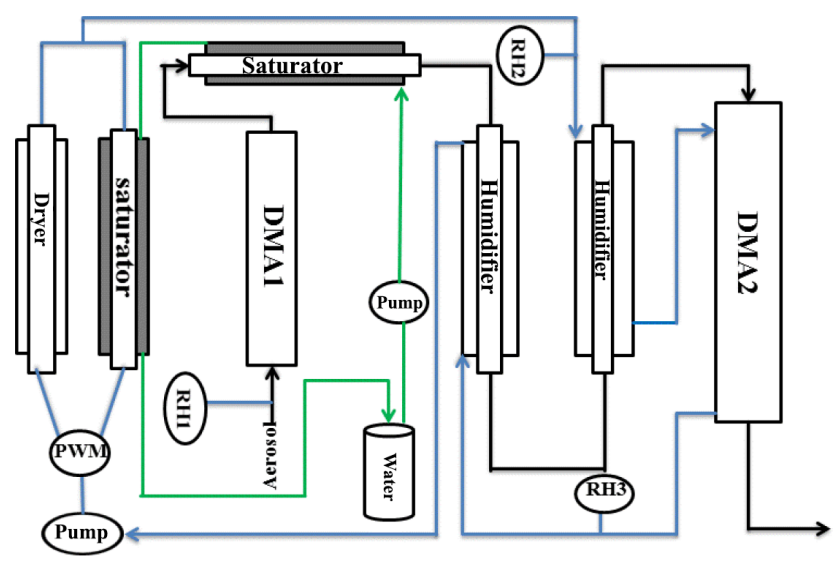

Figure 1. Schematic of the hygroscopicity tandem differential mobility analyzer (HTDMA) system. The sheath flow, aerosol flow, and water flow are represented by the blue, black, and green lines, respectively. PWM: pulse width modulator circuit.

lowed by a solid-liquid equilibrium (SLE) of AS needs to be considered to predict the effect of organic components in the mixed particles on the shift-suppression of AS efflorescence during aerosol dehumidification, i.e., referring to processes occurring along the dehydration branch of a HTDMA humidification-dehumidification cycle. The calculation of the ERH of AS in an organic-inorganic solution is thermodynamically related to the solubility limit, but it is not strictly deterministic (unlike the DRH) due to the stochastic nature of nucleation and growth of a crystal embryo. The molality of pure AS at saturation in an aqueous solution is known, e.g., measured by Apelblat (1993) at $298.15 \mathrm{~K}$ as $m_{\mathrm{AS}}^{\text {(sat) }}=5.790 \mathrm{~mol} \mathrm{~kg}^{-1}$, while measurements are most often not available for the solubility limit of AS in aqueous inorganic-organic systems. However, crystalline AS in equilibrium with an aqueous mixture demonstrates a specific molal ion activity product (IAP) in that solution at a given temperature and atmospheric pressure. For example, in the case of a ternary liquid mixture of levoglucosan $+\mathrm{AS}+$ water in SLE with a crystalline AS phase at a certain temperature $T$, a constant molal ion activity product $\operatorname{IAP}_{\mathrm{AS}}=\operatorname{IAP}_{\mathrm{AS}}^{(\text {sat }}(T)$ is established (necessary SLE condition). In this case the liquid mixture is a so-called saturated solution with respect to AS. While the molar amount of AS in a saturated solution depends on the other mixture constituents, the value of $\operatorname{IAP}_{\mathrm{AS}}^{\text {(sat) }}(T)$ is a function of temperature only since it is derived from the fixed chemical composition and associ- 
ated chemical potential of the crystalline phase. A reference value for $\operatorname{IAP}_{\mathrm{AS}}^{\text {(sat) }}(T)$ can therefore be calculated with the AIOMFAC model from an experimentally determined solubility limit of AS in known mixtures, such as the molality of AS at the point of saturation in the binary aqueous system (water + AS). The RH at which full dissolution of a solid phase upon humidification is just reached, the DRH, is directly related to the conditions at which a saturated solution becomes subsaturated upon addition of water. Here the degree of saturation with AS can be determined unambiguously using the computed value of $\mathrm{IAP}_{\mathrm{AS}}$ as a function of mixture composition and temperature. Making use of these thermodynamic relationships, the AIOMFAC-based equilibrium model is used to calculate the DRH and ERH of AS in the multicomponent system, as outlined below. Detailed information on the modeling of SLE and the IAP-based prediction of ERH is given in Zuend et al. (2011) and Hodas et al. (2016). Briefly, the ERH is determined based on the following equations:

$\mathrm{IAP}_{\mathrm{AS}}=\left[a_{\mathrm{NH}_{4}^{+}}^{(\mathrm{m})}\right]^{2}\left[a_{\mathrm{SO}_{4}^{2-}}^{(\mathrm{m})}\right]^{1}$

$\mathrm{IAP}_{\mathrm{AS}}^{[\text {crit] }}=c_{\mathrm{AS}} \times \mathrm{IAP}_{\mathrm{AS}}^{\text {(sat) }}$.

Here $a_{\mathrm{NH}_{4}^{+}}^{(\mathrm{m})}$ and $a_{\mathrm{SO}_{4}^{2-}}^{(\mathrm{m})}$ are the molal activities of the ammonium and sulfate ions in solution (Zuend et al., 2010). Molality basis is indicated by the superscript " $(\mathrm{m})$ " (which is not a mathematical exponent). IAP $_{\mathrm{AS}}^{\text {(sat) }}$ denotes the molal IAP of AS at salt saturation computed with the thermodynamic equilibrium model for any aqueous AS system at a certain temperature (here $298.15 \mathrm{~K}$ ). The calculated molal IAP at saturation of the corresponding binary salt solution is taken as the (known) reference value. The $\mathrm{RH}$ at which this $\mathrm{IAP}_{\mathrm{AS}}^{[\mathrm{sat}]}$ value is just reached in certain bulk solution at equilibrium with its environment (in contrast to $\mathrm{IAP}_{\mathrm{AS}}<\mathrm{IAP}_{\mathrm{AS}}^{\text {(sat) }}$ at higher RH) is the (bulk) DRH of AS. Similarly, the ERH is determined at the point of crystallization by a critical IAP value denoted as $\operatorname{IAP}_{\mathrm{AS}}^{\text {[crit] }}$ (Hodas et al., 2016), the value of $\operatorname{IAP}_{\mathrm{AS}}^{\text {[crit] }}>\mathrm{IAP}_{\mathrm{AS}}^{\text {[sat] }}$ expresses the need for reaching a critical IAP threshold (critical level of AS supersaturation) for highly likely nucleation and growth of a new crystalline AS phase. The multiplication factor $c_{\mathrm{AS}}$ is used as a constant coefficient relating the IAP at AS saturation to the one expected at the point of crystallization in aqueous mixed particles. From the comparison of laboratory measurement of ERH for aqueous AS solution to the AIOMFAC-predicted $\mathrm{IAP}_{\mathrm{AS}}$ at that $\mathrm{RH}$, the value of $c_{\mathrm{AS}} \approx 30$ was determined; this value is in particular applicable to submicron-sized AS droplets (Zardini et al., 2008; Ciobannu et al., 2010).

An analogous approach is used for the ERH predictions with the E-AIM model; however, since E-AIM provides activity coefficients and activities on a mole fraction basis, denoted here by the superscript " $(x)$ " (rather than molality basis), the value of $c_{\mathrm{AS}}^{(x)}$ needs to be determined separately for that model. Expressing Eq. (1) using mole-fraction-based activities of $\mathrm{NH}_{4}^{+}$and $\mathrm{SO}_{4}^{2-}$ and comparison to the $\mathrm{IAP}_{\mathrm{AS}}^{(\mathrm{sat}, \mathrm{x})}$ and $\mathrm{IAP}_{\mathrm{AS}}^{(\mathrm{crit}, \mathrm{x})}$ computed by E-AIM for AS at the experimental solubility limit and ERH in aqueous AS solutions, a value of $c_{\mathrm{AS}}^{(x)} \approx 40$ was determined for the calculation with E-AIM.

As discussed by Lei et al. (2014), prediction of HGFs with E-AIM includes a sophisticated composition-dependent solution density model, which considers the nonideality effects on apparent molar volumes used for the calculation of the solution density in mixed organic-inorganic systems (Clegg and Wexler, 2011a, b). The AIOMFAC-based model applies a simpler solution density treatment by assuming that the partial molar volumes of solution species are independent of nonideal interactions, i.e., the mixed solution density is calculated based on linear additivity of pure component solid or liquid volume contributions to obtain the HGF at a given RH. Differences in the density models are expected to lead to relatively small differences, typically on the order of the HTDMA measurement error or less (e.g., Fig. 2a), in the application to HGF predictions, as demonstrated by Lei et al. (2014) for the case of diameter vs. mass-based HGFs of AS droplets. Both models include sophisticated sets of equations to compute activity coefficients of all solution components in a thermodynamically consistent manner.

\section{$2.4 \kappa$-Köhler theory and computation of the hygroscopicity parameter $\kappa$}

The hygroscopicity parameter, $\kappa$, is commonly used to characterize the relative hygroscopicities of individual aerosol particles, known mixtures, or complicated atmospheric aerosols (Petters and Kreidenweis, 2007) and to model the composition dependence of the solution water activity. The saturation ratio, $S$, in the traditional Köhler equation (Eq. 3) over an aqueous droplet is calculated from

$S=a_{\mathrm{w}}\left(\frac{4 \sigma_{\mathrm{s}} M_{\mathrm{w}}}{\operatorname{RT} \rho_{\mathrm{w}} D_{\mathrm{wet}}}\right)$,

where $a_{\mathrm{w}}$ is the mole-fraction-based water activity in solution and $M_{\mathrm{w}}$ and $\rho_{\mathrm{w}}$ are the molar mass of water and the density of pure water in the liquid state at temperature $T$, respectively. $D_{\text {wet }}$, the wet particle diameter at a given $\mathrm{RH}$, is defined by $D_{\text {wet }}=\mathrm{HGF} \times D_{0}$. $D_{0}$ denotes the diameter at dry conditions at a RH below $5 \%$. The solution surface tension is denoted by $\sigma_{\mathrm{s}}$. In the $\kappa$-Köhler theory, the bulk solution water activity is described by a single parameter $\kappa$, with the hygroscopic parameter of the overall mixture related to Eq. (3) by

$\kappa_{\mathrm{HGF}}=1-\mathrm{HGF}^{3}+\frac{\mathrm{HGF}^{3}-1}{S} \exp \left[\frac{4 \sigma M_{\mathrm{w}}}{\mathrm{RT} \rho_{\mathrm{w}} D_{\mathrm{wet}}}\right]$.

This expression describes effective values of $\kappa_{\mathrm{HGF}}$ as a function of droplet diameter and HGF at a certain saturation ratio. In turn, known (measured) solution $\kappa_{\mathrm{HGF}}$ values or component-specific $\kappa_{i}$ values can be used to parameterize or 

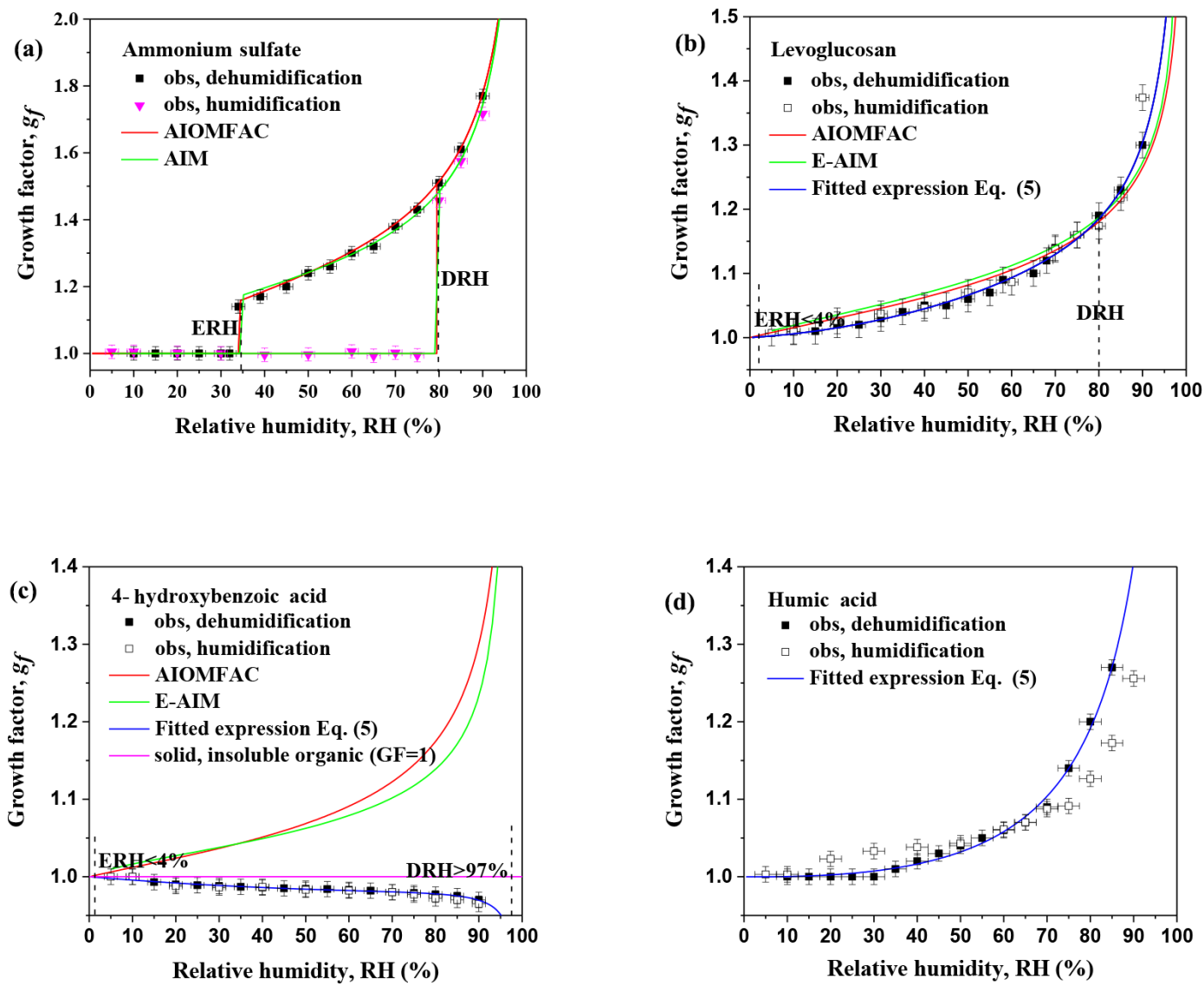

Figure 2. Hygroscopic growth, deliquescence, and efflorescence of aerosol particles. Hygroscopic growth factors of (a) ammonium sulfate (AS), (b) levoglucosan, (c) 4-hydroxybenzoic acid, and (d) humic acid aerosol particles with a dry diameter of $100 \mathrm{~nm}$ (open, black square). In this study, the green curves show E-AIM predictions, the red curves the AIOMFAC predictions, and the blue lines the fitted expression (Eq. 5).

predict the HGF curve of a mixture (Petters and Kreidenweis, 2007).

\subsection{GF data fit}

As described by Dick et al. (2000), the relationship between measured HGFs and water activity can alternatively be parameterized by the following expression:

$\mathrm{HGF}=\left[1+\left(c_{1}+c_{2} \times a_{\mathrm{w}}+c_{3} \times a_{\mathrm{w}}^{2}\right) \frac{a_{\mathrm{w}}}{1-a_{\mathrm{w}}}\right]^{\frac{1}{3}}$.

By substitution of Eq. (3) for $a_{\mathrm{w}}$ in Eq. (5) and a fit to the measured HGF, the three adjustable coefficients $c_{1}, c_{2}$, and $c_{3}$ of Eq. (5) were determined. The coefficient values are given in Table 3 for the different organic compounds considered.

\subsection{GF prediction by ZSR}

The ZSR mixing rule is widely used to approximate the water uptake of mixed systems by assuming additivity of the water uptake of each individual component in the mixed particles at a given RH (e.g., Malm and Kreidenweis, 1997). $\mathrm{HGF}_{\text {mix }}$ is based on the $\mathrm{HGF}_{j}$ of pure components $j$ and their corresponding volume fraction, $\varepsilon_{j}$, in the mixed particles.

$\mathrm{HGF}_{\text {mix }}=\left[\sum_{j} \varepsilon_{j}\left(\mathrm{HGF}_{j}\right)^{3}\right]^{\frac{1}{3}}$

\section{Results and discussion}

\subsection{GF of single-compound systems}

Figure 2a shows the measured diameter growth factors of AS particles as a function of RH for both humidification and dehumidification conditions. The measured ERH of $100 \mathrm{~nm}$ AS particles is approximately $35 \% \mathrm{RH}$ at $298.15 \mathrm{~K}$. The model-predicted GF and solid-liquid phase transition of AS are in relatively good agreement with the experimental data and, in particular, the efflorescence (crystallization) of AS is captured by the AIOMFAC and E-AIM models. The good model-measurement agreement for the ERH is of course expected, since the aqueous AS system serves as the reference 
Table 3. Coefficients $\left(c_{1}, c_{2}, c_{3}\right)$ of the fitted growth factor parameterization (Eq. 5) as follows.

\begin{tabular}{lrrr}
\hline Chemical compounds & $c_{1}$ & $c_{2}$ & $c_{3}$ \\
\hline Levoglucosan & 0.12868746 & 0.36582023 & -0.39840382 \\
4-Hydroxybenzoic acid & $-1.389967 \times 10^{-1}$ & $2.325586 \times 10^{-1}$ & $-9.891943 \times 10^{-2}$ \\
Humic acid & $-1.618304 \times 10^{-2}$ & $2.202483 \times 10^{-1}$ & $2.005134 \times 10^{-2}$ \\
\hline
\end{tabular}

system for determining the value pairs of $\operatorname{IAP}_{\mathrm{AS}}^{(\mathrm{sat})}$ and $c_{\mathrm{AS}}$ on a molality and mole fraction basis for use with AIOMFAC and E-AIM, respectively (Sect. 2.3). An ERH of 31 to $40 \% \mathrm{RH}$ was reported by other groups for a range of particle sizes and experimental techniques (Zardini et al., 2008; Ciobanu et al., 2010). There are several factors that contributed to the variability in reported ERH values, such as particle size, temperature, solution impurities, and the stochastic nature of the homogeneous or heterogeneous nucleation of a crystalline phase near ERH (Ciobanu et al., 2010).

In Fig. 2b, upon dehydration, no efflorescence of the levoglucosan aerosol particles is observed even at a RH below $10 \%$. The agreement of the HGF between the hydration and dehydration processes demonstrates that these particles equilibrate with the surrounding water vapor under these moisture conditions. For example, the measured diameter growth factors of levoglucosan particles at 80,60 , and $30 \% \mathrm{RH}$ are $1.19,1.09$, and 1.03, respectively, which are similar to results obtained for the hydration process of such particles. Levoglucosan has a DRH of $\sim 80$ to $83 \%$ (for a bulk system) at 293 to 298 K (Mochida and Kawamura, 2004; Zamora et al., 2011). The similarity of diameter growth factors both under hydration and dehydration conditions even below the DRH of levoglucosan is explained by the lack of crystallization of levoglucosan upon drying to low $\mathrm{RH}$ and the presence of a metastable supersaturated aqueous levoglucosan solution in both the hydration and dehydration modes for experiments initiated with liquid solution droplets (Mochida and Kawamura, 2004; Chan et al., 2005; Svenningsson et al., 2006). A possible reason for a persistent metastable supersaturated solution state is that levoglucosan particles remain liquid (possibly a viscous liquid state) upon drying to below $5 \% \mathrm{RH}$, which was also observed previously with a reported ERH $<4 \%$ RH (Mochida and Kawamura, 2004; Chan et al., 2005). Also, the measured diameter growth factors of levoglucosan particles are in good agreement with those estimated from the standard UNIFAC model within the E-AIM model and the AIOMFAC model, within experimental uncertainty. The UNIFAC models within E-AIM and AIOMFAC are based on the original model expressions by Fredenslund et al. (1975) and both include the extensive parameter set by Hansen et al. (1991) as well as revised parameters for certain group interactions of water with carboxyl and hydroxyl groups by Peng et al. (2001). Of relevance for levoglucosan and other sugar-like compounds, the AIOMFAC model also contains certain revised group parameters for hydroxyl groups and special alkyl groups for their interactions with water, introduced by Marcolli and Peter (2005) for polyols, as further detailed in Zuend et al. (2011). However, the molecular structure of levoglucosan with several polar functional groups in close vicinity may account for a small deviation between modeled and measured HGFs at RH below $70 \%$ because intramolecular interactions are not fully considered by these models.

The measured diameter growth factors of 4hydroxybenzoic acid particles shown in Fig. 2c demonstrate an untypical increase in diameter of 4-hydroxybenzoic acid particles during dehumidification from 90 to $10 \% \mathrm{RH}$, which is consistent with previous diameter growth factors for a few solid particles (Mochida and Kawamura, 2004). The organic particles measured are likely always in the effloresced, i.e., crystalline, state apparently even at high RH. The apparent increase in diameter during dehumidification may be explained by particle shape restructuring since the (poly)crystalline particles are likely nonspherical at dry conditions but may become more sphere-like in shape when exposed to higher RH (Mikhailov et al., 2004). Also, no ERH of 4-hydroxybenzoic acid in the dehydration mode was observed during the experiments; the likely reason is that the highest RH reached in the humidifier was approximately $98 \%$, which may be below the ERH of 4-hydroxybenzoic acid, reported as above $98 \% \mathrm{RH}$ in another study (Mochida and Kawamura, 2004). As discussed previously by Lei et al. (2014), our HTDMA experiments are carried out such that $\mathrm{RH}=98 \%$ is reached initially before dehumidification to a series of RH values at set point RH2 (90-5\% RH); the crystallization of the organic, however, could occur at above $90 \%$ RH. In addition, deviations between measurements and model prediction are obvious in Fig. 2c. The observations by far surpass the expected error in model performance, which is typically less than 0.05 in $\mathrm{HGF}$ units for $\mathrm{RH}<85 \%$, as also indicated by an intercomparison of the AIOMFAC and E-AIM predictions in Fig. 2c and much-improved model-measurement agreement for the case of mixed 4-hydroxybenzoic acid + AS particles shown in Fig. 4 (discussed in Sect. 3.2. 2). However, note that the validity of the shown model predictions in Fig. 2c depends on whether the assumption of a liquid solution droplet is plausible. Therefore, it is no surprise that the model-predicted curves deviate from the experimental hygroscopic behavior of 4-hydroxybenzoic acid particles. Morphology effects, such 
as the restructuring of nonspherical polycrystalline particles over a certain RH range or liquid-liquid phase-separated particles of nonspherical shapes, have been discussed by several groups (Sjogren et al., 2007; Reid et al., 2011; Lei et al., 2014). In the case of hygroscopic growth of pure 4-hydroxybenzoic acid particles and mixtures of 4-hydroxybenzoic acid with ammonium sulfate, an offset between measurement and model predictions was observed both in the RH range below the deliquescence of the particles and above it, i.e., above $80 \%$ RH (Lei et al., 2014). It is suggested that deviations are primarily caused by a change in solid-state particle morphology during hydration, leading to a restructuring of the polycrystalline particle shape towards a more compact, near-spherical shape as the RH approaches the particle deliquescence point. This would explain rather uncommon HGF values of less than 1.0 at an elevated RH, also shown in Fig. 2c. Similar behavior was found for experimental growth factors of mixtures containing adipic acid and AS and systematic deviations between the associated ZSR predictions and observations by Sjogren et al. (2007). Thus, while experimental data hint to the possible influence of nonspherical particles and their humidity-induced restructuring as a source of uncertainty, model predictions of HGF, such as those with the AIOMFAC model, assume by default a spherical particle shape even for solid phases and/or in cases in which liquid-liquid phase separation (LLPS) is present.

The measured HGF curves of humic acid aerosol particles during dehumidification and humidification measurements do not agree very well within experimental uncertainty, in particular above $70 \% \mathrm{RH}$. For instance, the growth factor of humic acid aerosol particles at $80 \% \mathrm{RH}$ is 1.2 according to the dehumidification measurement, which is higher than the HGF of humic acid particles in the humidification mode at the same RH. Humic acid aerosol particles shrink continuously due to loss of water content in the range from 90 to $10 \%$ RH. For example, a stepwise change in the water absorption and desorption behavior within different $\mathrm{RH}$ ranges was observed in the case of Nordic aquatic fulvic acid (NAFA) and Suwannee River fulvic acid by Chan and Chan (2005). These hygroscopic behaviors suggest that humic acid particles and structurally similar compounds retain some water down to the low RH levels achieved in the instruments (imperfect drying during particle residence in the instrument). In addition, the experimental growth factor of humic acid aerosol particles during dehumidification can be represented well by fitting Eq. (5) to the measurements. The determined fit parameters are listed in Table 3. The humic acid sample used (Aldrich, 99\%) is a mixture of different polycarboxylic acids of undefined chemical structure. However, specific information on the chemical structure and mixture composition is necessary for corresponding model predictions with AIOMFAC and E-AIM. Therefore, no such model calculations are shown in Fig. 2d.

\subsection{GF of mixtures of organic surrogate compounds + ammonium sulfate}

Biomass burning aerosol particles are likely mixtures of a diversity of inorganic constituents and organic compounds in the atmosphere. For example, particles may consist of a combination of AS mixed with low-volatility and semi-volatile organics from biomass burning emissions (Lee et al., 2003; Zhang et al., 2007; Pratt and Prather, 2010). Different water solubilities and hygroscopic behavior of distinct organic compounds may affect the HGFs of mixtures of partially or fully dissolved inorganic and organic components. For example, Bodsworth et al. (2010) studied the effect of different mass fractions of citric acid on the efflorescence properties of mixed citric acid-ammonium sulfate particles at lower temperatures and concluded that adding citric acid decreases the ERH of ammonium sulfate in the mixed aerosol particles. These hygroscopic behaviors of mixed aerosol particles, including phase transition in the range from moderate to low $\mathrm{RH}$, are the focus of attention in this study.

\subsubsection{Mixed system: levoglucosan + ammonium sulfate}

Figure 3 shows measured growth factors of mixed aerosol particles containing levoglucosan + ammonium sulfate with different dry-state organic-to-inorganic mass ratios $(1: 3,1$ : $1,3: 1)$ in the $\mathrm{RH}$ range from 90 to $10 \%$. There is a reduction in the diameter growth factor of aerosol particles containing levoglucosan and AS with increasing levoglucosan mass fraction, as expected from a ZSR-like additivity concept of hygroscopicity. When the concentration of levoglucosan is low ( $25 \mathrm{wt} \%$ ), a clear efflorescence signature of AS is found, within the ERH shifting to a higher RH (40-45\%) in comparison to the ERH of pure AS occurring at 33-35\% RH (Fig. 3a). A similar phenomenon has been found for the certain mixtures of $\mathrm{NaCl}$ and NAFA, in which the crystallization of $\mathrm{NaCl}$ shifted to higher RH by mixing with NAFA at a mass ratio of $1: 1$ (Chan and Chan. 2003). With an increasing mass fraction of levoglucosan (i.e., 50 and $75 \mathrm{wt} \%$ ), the mixtures release water gradually and no crystallization of AS was observed. Although a small step in the growth factor curve might have occurred (indicative of the crystallization of AS), it cannot be detected with sufficient certainty by our measurement setup. The rather high viscosity of solutions containing levoglucosan is expected to increase considerably toward RH (Marshall et al., 2016). This increase in viscosity might impede the crystallization of AS in the mixed systems on the timescale of the experiment. Mass transfer limitation effects on the deliquescence or efflorescence process of crystalline organic particles and the water uptake or evaporation have been investigated in several experimental studies (Peng et al., 2001; Choi and Chan, 2002; Chan and Chan, 2005; Sjogren et al., 2007; Zardini et al., 2008; Ciobanu et al., 2010; Smith et al., 2012; Mikhailov et al., 2013; Hodas et al., 2015). Mass transfer limitations may impact the outcome of experiments 

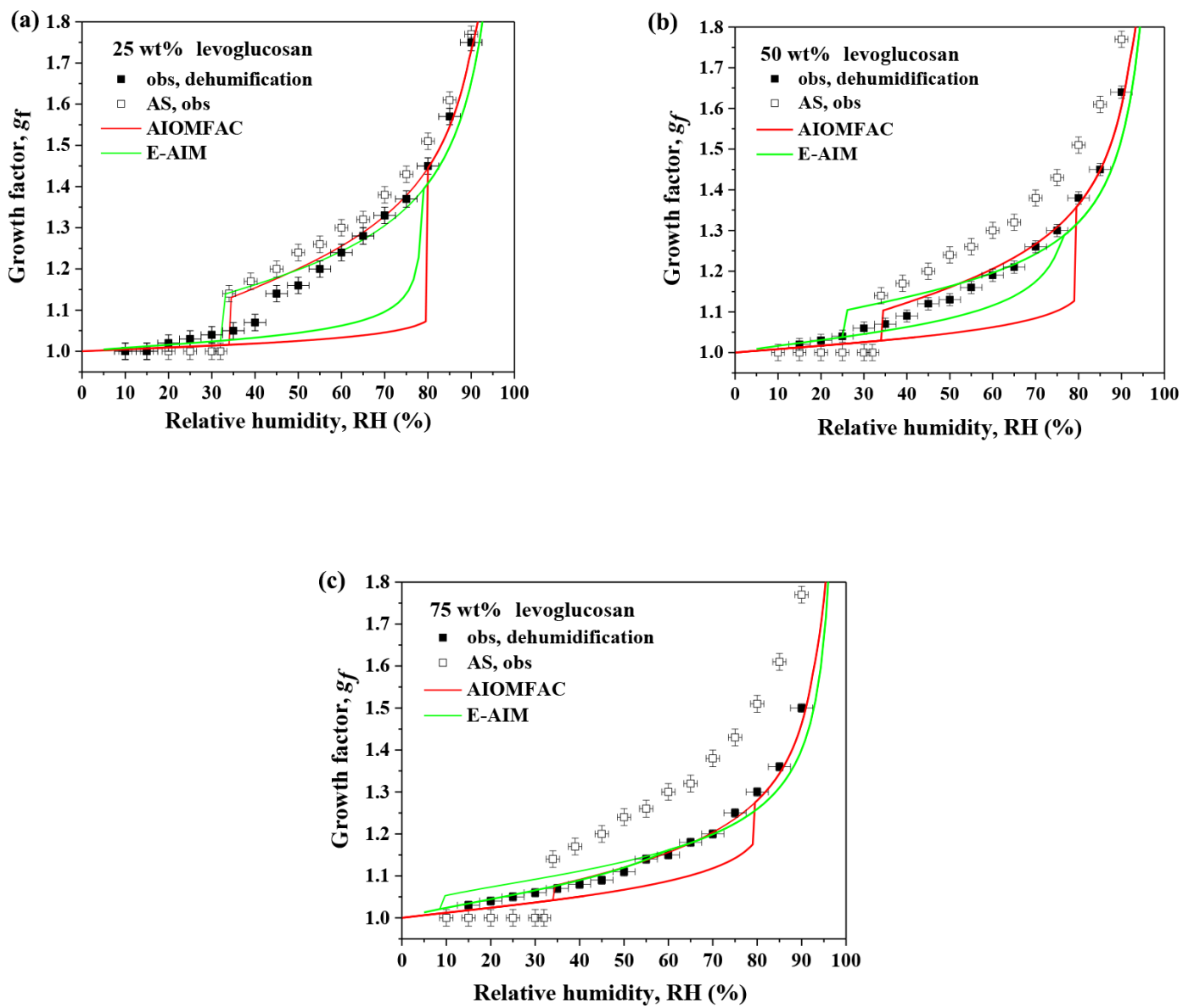

Figure 3. Hygroscopic growth, efflorescence of aerosol particles, and model predictions represent the diameter growth factor during dehydration experiments in the range from 90 to $5 \% \mathrm{RH}$ at $298.15 \mathrm{~K}(\mathbf{a}, \mathbf{b}, \mathbf{c})$. Hygroscopic growth curves of mixtures consisting of levoglucosan and ammonium sulfate (solid symbols) at three different dry-state mass fractions for particles of an initial dry diameter of $100 \mathrm{~nm}$ at $\mathrm{RH}<5 \%$ as compared to that of pure ammonium sulfate (open symbols, "AS, obs"). AIOMFAC-based model predictions for bulk systems are shown in red. E-AIM predictions are shown in green.

significantly if the characteristic timescales for equilibration are similar to or larger than the residence time of particles in the experimental setup. In this study, the total residence time of the aerosol sample during the equilibration phase before entering the DMA2 is about $8 \mathrm{~s}$. In order to improve the probability that the particles reach equilibrium with the target RH during this residence time, the monodisperse aerosol selected by DMA1 is first humidified to $98 \% \mathrm{RH}$. The aerosol particles are then exposed to a lower target RH by a twostep process using double Nafion tubes. Kerminen (1997) estimated the necessary residence time for achievement of water equilibrium of aqueous droplets to be between 0.005 and $0.1 \mathrm{~s}$ (water uptake coefficient $\alpha_{\mathrm{w}}=0.001,25^{\circ} \mathrm{C}$ ) for 100 and $500 \mathrm{~nm}$ particles, respectively. Therefore, the typical residence time of a few seconds in the humidification or dehumidification section in a HTDMA measurement is assumed to be sufficient for most equilibrium hygroscopicity measurements (Brooks et al., 2004; Mikhailov et al., 2004). Moreover, our HGF results for the three pure organic com- ponents are in good agreement with data by Mochida and Kawamura, (2004), Brooks et al. (2004), and Chan and Chan (2005) conducted with different techniques and/or residence times. However, there are cases in which water equilibration could be impeded substantially in the presence of highly viscous or glassy particles at low RH, e.g., for ternary sucrose $+\mathrm{NaCl}+$ water particles of $>6 \mu \mathrm{m}$ in diameter studied by Bones et al. (2012), who report an equilibration timescale $>1000 \mathrm{~s}$ for such particles. Note that, aside from viscosity, there is an important size dependence of the particles on the equilibration timescale (e.g., Koop et al., 2011). For aqueous $100 \mathrm{~nm}$ particles used in HTDMA experiments at room temperature, Bones et al. (2012) indicate that the equilibration timescale for water is likely only of concern for $\mathrm{RH}<10 \%$ in such an instrument. We therefore conclude that the residence time of $8 \mathrm{~s}$ is very likely sufficient to allow for equilibrium HGF measurements in dehydration mode, at least down to $10 \% \mathrm{RH}$ (when starting with aqueous solution droplets). 
Mass transfer effects in hygroscopicity measurements of aerosol particles during hydration conditions have been encountered previously, particularly when a solid-liquid phase transition (deliquescence) is involved (Peng et al., 2001; Chan and Chan, 2005). For example, Peng et al. (2001) observed, in electrodynamic balance experiments under conditions of very slow humidification, that glutaric acid aerosol particles showed a deliquescence phase transition in the $\mathrm{RH}$ range from 83 to $85 \%$ over the course of several hours. This is a much longer time span than that of $\sim 40 \mathrm{~min}$ for the deliquescence of other super-micron sized dicarboxylic acid particles (e.g., malonic acid) in electrodynamic balance experiments. This observation indicates that the solid-liquid phase transition of glutaric acid particles may likely be mass transfer limited during the hydration process. In this context, it is possible that the deliquescence of initially solid, pure 4hydroxybenzoic acid particles at $\mathrm{RH}>97 \%$ is further impeded by slow dissolution, which could have led to the absence of deliquesced particles (Fig. 2c) on an experimental timescale.

In addition, the measured diameter growth factors of mixtures of levoglucosan and AS are compared to calculations of hygroscopic growth by the E-AIM and AIOMFAC models. The E-AIM prediction is in relatively good agreement with results from the HTDMA measurement but typically overestimates the water content of particles consisting of organic-AS mixtures at the RH range close to the ERH of AS. The liquid-solid phase transition of AS in the mixed particles is considered in the E-AIM assumptions as described in Sect. 2.3. There is a more distinct shift in ERH of AS with higher mass fractions of levoglucosan. In the case of the AIOMFAC and E-AIM model predictions, it is assumed that the diameter growth factor contribution from AS is zero below the predicted ERH, i.e., there the growth factor deviation from 1.0 is solely due to the organic water uptake. The model prediction shows a slight deviation from the measurements, which may be in part due to (i) model uncertainty in the correct description of the hygroscopicity of levoglucosan, (ii) incomplete representation of AS + levoglucosan interactions in aqueous solutions, and (iii) measurement error. Also, in the case of mixtures consisting of AS and levoglucosan with an organic-to-inorganic dry mass ratio of $3: 1$ ( $75 \mathrm{wt} \%$ levoglucosan of dry particle composition), the underestimation of the growth factor by the AIOMFAC model at $\mathrm{RH}<35 \%$ in comparison to the measurements is explained in part by the model prediction of AS efflorescence (which seems to be absent in the measurements). However, with a decreasing AS mass fraction, the hygroscopic behavior of levoglucosan dominates the diameter growth factors of the mixtures, in relative agreement with the AIOMFAC-modeled "dehydration branch" prediction. Minor differences in the AIOMFAC prediction vs. measurement for diameter growth factors of mixed levoglucosan and AS in the RH range of 35-25\% here might be attributed to mixture viscosity effects at the higher levoglu- cosan contents, which may suppress the efflorescence of AS in the mixed systems on an experimental timescale or it could simply be due to sufficient miscibility of dissolved AS in the aqueous levoglucosan solution (beyond that predicted by the model), such that a small step change due to AS efflorescence could be beyond the experimental detection range. As a result, accounting for the effect of the organic components on the diameter growth factors of mixtures within aerosol particles is crucial to accurately modeling the equilibrium hygroscopic behavior.

\subsubsection{Mixed system: 4-hydroxybenzoic acid + ammonium sulfate}

Mixtures of 4-hydroxybenzoic acid + AS with different organic mass fractions $(25,50,75 \mathrm{wt} \%)$ exhibit a gradual water desorption before the AS fraction of the particle effloresces at a certain RH. With an increasing 4-hydroxybenzoic acid mass fraction, no discontinuity step at the corresponding ERH in the dehydration curve of mixtures is observed. This suggests the presence of 4-hydroxybenzoic acid in the liquid state retards or offsets the efflorescence of AS in the mixtures. An interesting yet contrasting phenomenon was observed for the hydration process of aerosol mixtures containing 4-hydroxybenzoic acid and AS by Lei et al. (2014). For the case of these mixtures during moistening, the deliquescence of AS in the mixed particles remains unaffected, within experimental resolution, by the presence of 4-hydroxybenzoic acid (Lei et al., 2014). Similar behavior has been observed for particles containing certain organic acids of limited water-solubility mixed AS (Choi and Chan, 2002; Chan and Chan, 2003). For example, mixtures for succinic acid + AS showed no substantial influence on the deliquescence RH of $\mathrm{AS}$ in the hydration process (Choi and Chan, 2002). However, a clear RH shift of the deliquescence phase transition of AS or sodium chloride was determined for mixed particles containing organic acids of higher water solubility and $\mathrm{O}: \mathrm{C}$ ratio, such as citric acid and malonic acid (e.g., Choi and Chan, 2002). The DRH and ERH of pure organics and AS in the mixed organic-AS particles are summarized in Table 4; the measurements indicate that 4-hydroxybenzoic acid has a significant effect on the efflorescence of AS when present in a sufficient amount. Also, there is a clear reduction in the diameter growth factors prior to crystallization for mixtures with increasing 4hydroxybenzoic acid mass fraction.

The measurements of mixtures consisting of 4hydroxybenzoic acid and AS are compared with model predictions based on different assumptions about the phase state of the organic component since the deviation from measurements might partly be explained by a transition in the physical state of the organic component. The E-AIM model prediction refers to a system in which the mixture of 4-hydroxybenzoic acid is assumed to be in the liquid state at all RH levels and in which the efflorescence of 
Table 4. Experimental studies of organic and ammonium sulfate (AS) deliquescence and efflorescence RH from this work and previous studies at $298 \mathrm{~K}$.

\begin{tabular}{lrrr}
\hline Signal compound/mixture & $\begin{array}{r}\text { Organic mass } \\
\text { fraction } \\
(\%)\end{array}$ & $\begin{array}{r}\text { Deliquescence relative } \\
\text { humidity of AS or } \\
\text { organic in the } \\
\text { mixed particle }\end{array}$ & $\begin{array}{r}\text { Efflorescence relative } \\
\text { humidity of AS or } \\
\text { organic in the } \\
\text { mixed particle }\end{array}$ \\
\hline Levoglucosan & - & $80 \% \%^{\mathrm{a}, \mathrm{b}}$ & $<4 \%$ \\
\hline Levoglucosan + AS & 25 & $80 \%$ & $45 \%$ \\
& 50 & - & - \\
\hline 4-Hydroxybenzoic acid & 75 & - & - \\
\hline 4-Hydroxybenzoic & - & $80 \%$ & $<4 \%$ \\
acid + AS & 25 & $80 \%$ & $35 \%$ \\
& 50 & $80 \%$ & - \\
\hline Humic acid & 75 & $-\mathrm{b} \%$ & - \\
\hline Humic acid + AS & - & $80 \%$ & $35 \%$ \\
& 20 & $80 \%$ & $35 \%$ \\
& 50 & & $35 \%$ \\
\hline
\end{tabular}

\footnotetext{
a The DRH and ERH of pure organic components.

${ }^{b}$ Mochida and Kawamura (2004).

${ }^{\mathrm{c}}$ Zamora et al. (2011).
}

AS is considered. Neglecting the potential efflorescence of the organic component in the dehydration branch makes a systematic offset more obvious prior to the efflorescence of AS. A good E-AIM model-measurement agreement occurs below the predicted ERH of AS for mixed particles. The overestimation of HGFs before the efflorescence of AS is explained by the AIOMFAC model prediction with distinct assumptions about the phase state of the organic component. A possible reason for the departure of model-measurement agreement at $\mathrm{RH}<80 \%$ is that there two liquid-to-solid phase transitions occur in the mixed particles: a gradual one for the organic component and a step-like one for AS at a lower RH. This phenomenon is shown in the grid square range in Fig. 4 and is supported by comparison of the measured HGF data with AIOMFAC-based predictions for two assumptions about the organic phase state, especially in the case of mixtures with 50 and $75 \mathrm{wt} \%$ organic. We acknowledge that the model predictions of the HGF curves for the two organic phase state assumptions differ within experimental error for the case shown in Fig. 4a, indicating that alternative explanations, such as model-measurement uncertainty in the absence of a liquid-solid phase transition, could explain the observations. In the Fig. 4b, good agreement between measurements and the AIOMFAC model prediction with liquid organic assumption is found for $\mathrm{RH}>65 \%$, while for $\mathrm{RH} \leq 60 \%$ the experimental data agree very well with the dashed red model curve for the case with consideration of a solid organic component. This suggests that crystallization followed by gradually increasing partitioning of organic from the solution to the solid organic phase occurs in the range from 70 to $60 \% \mathrm{RH}$ under conditions of dehumidification. Similarly, a liquid-to-solid phase transition occurs for the cases with an organic: AS mass ratio of $3: 1$ in the range from 80 to $50 \%$ RH. Meanwhile, AS remains dissolved in a supersaturated aqueous solution phase. Moreover, the AIOMFAC-based equilibrium model predicts a LLPS to occur at a RH below 90\% for the calculation cases with the assumption of the organic in the liquid state (for all three organic mass fractions in Fig. 4). This prediction leads to a liquid phase enriched in 4-hydroxybenzoic acid with some water and AS dissolved and a coexisting liquid phase enriched in AS and water. The onset of the LLPS during dehumidification leads to the kink in the red model curve near $90 \% \mathrm{RH}$ since the slope of the HGF curve with RH changes in a non-smooth manner at the point of the LLPS phase transition. This change in slope is not noticeable from the experimental data alone, but the model-measurement comparison for the range above $80 \%$ RH shows very good agreement. The two liquid phases will likely remain separated until nucleation of a crystalline 4-hydroxybenzoic acid phase occurs followed by gradual partitioning of the organic acid to the solid phase with decreasing $\mathrm{RH}$ (to $\sim 50 \% \mathrm{RH}$ ), at which point only a single liquid phase (an aqueous AS phase with a tiny amount of dissolved humic acid) will remain until efflorescence of AS occurs. Above $\sim 90 \% \mathrm{RH}$, a single, homogeneous liquid 

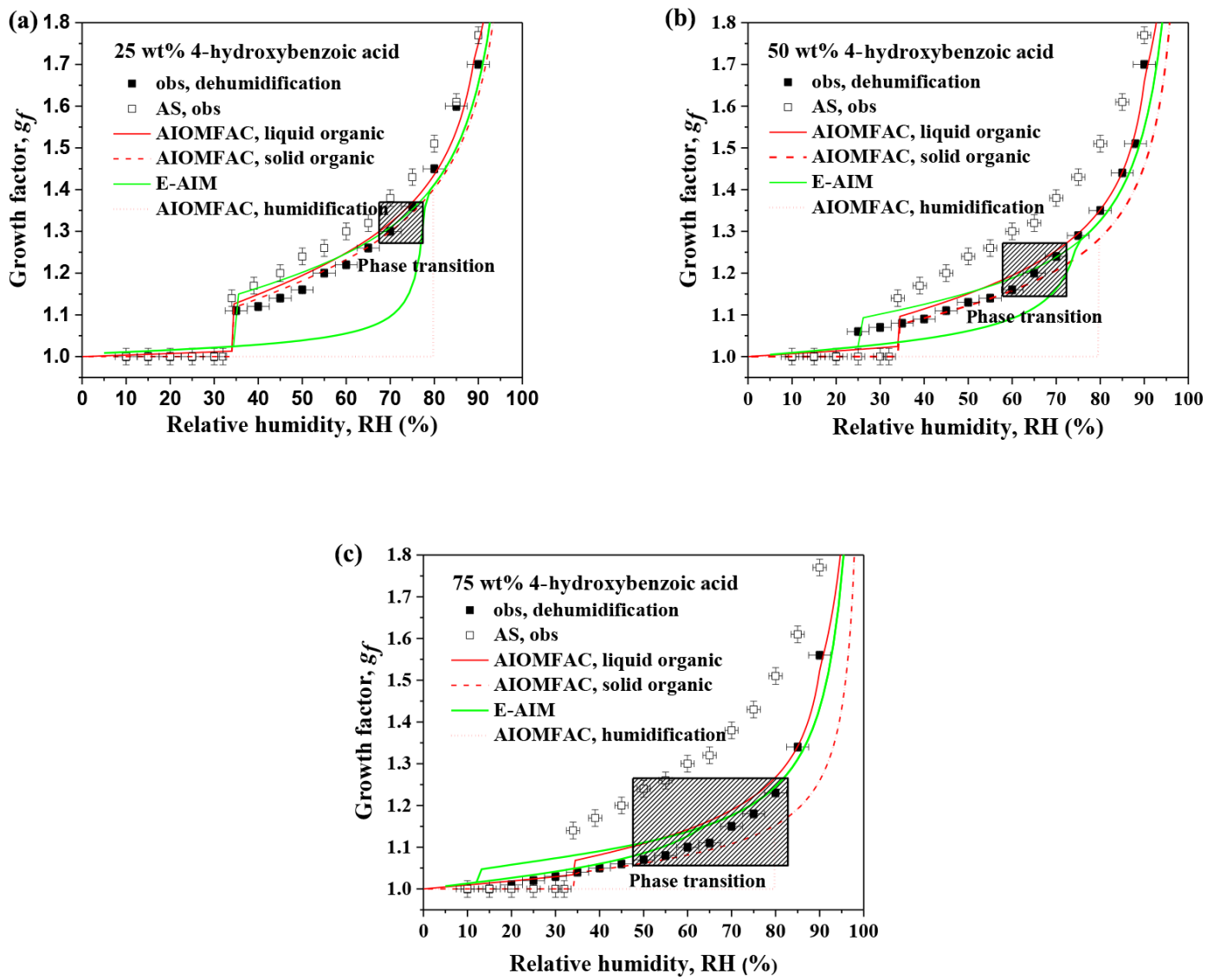

Figure 4. Hygroscopic growth factors, efflorescence of behavior, and model predications for dehydration experiments in the range from 90 to $5 \%$ RH at $298.15 \mathrm{~K}(\mathbf{a}, \mathbf{b}, \mathbf{c})$. Hygroscopic growth curves of mixtures consisting of 4-hydroxybenzoic acid and ammonium sulfate (solid symbols) at three different dry-state mass fractions (initial dry diameter of $100 \mathrm{~nm}$ at $\mathrm{RH}<5 \%$ ) as compared to those of pure ammonium sulfate (open symbols). AIOMFAC-based model predictions for bulk systems are shown in red; E-AIM-predictions are shown in green for the case assuming that 4-hydroxybenzoic acid remains in the liquid state. Shaded rectangle: RH range of gradual crystallization of 4-hydroxybenzoic acid.

phase is predicted to exist. Interestingly, this AIOMFAC model-measurement comparison (Fig. 4, especially panels b and c) provides reasonable evidence that 4-hydroxybenzoic acid remains dissolved and therefore in a liquid phase state at high $\mathrm{RH}$ in the mixed particles upon dehumidification (it is present in both liquid phases below $90 \% \mathrm{RH}$, but highly enriched in the AS-poor phase). In contrast, in the case of pure 4-hydroxybenzoic acid aerosol particles, particles exposed to an initial RH of $\geq 90 \%$ remain in the solid state (or crystallize at $\mathrm{RH}>90 \%$ ) in the dehydration mode (Fig. 2c). What factors contribute to keeping the organic in the liquid solution? It is possible that the aerosols generated with those mixed solutions allowed the 4-hydroxybenzoic acid to fully dissolve as the AS provided substantial particle-phase water content (within short time) into which the organic could be dissolved and may have then further contributed to water uptake associated with the organic's hygroscopicity (unlike in the case of the pure 4-hydroxybenzoic acid particles). The 4-hydroxybenzoic acid remains dissolved in the mixture, possibly supersaturated with respect to the crystalline organic state (similar to how AS stays supersaturated at RH below the DRH during drying). We consider this a reasonable explanation for the observed HGF data from the HTDMA in comparison to the different AIOMFAC-based curves.

\subsubsection{Mixed system: humic acid + ammonium sulfate}

Figure 5 shows that the experimental diameter growth factors of mixtures consisting of humic acid and AS with dry mass ratios of $1: 3,1: 1$, or $3: 1$ decrease with an increasing mass fraction of humic acid at RH $>35 \%$. For example, at $35 \% \mathrm{RH}$ the measured HGF are 1.1, 1.05, and 1.05 for the particles consisting of 25,50 , and $75 \mathrm{wt} \%$ humic acid. In comparison, the diameter growth factor of pure supersaturated AS particles is $\sim 1.13$ just prior to efflorescence of AS. Humic acid, unlike levoglucosan and 4-hydroxybenzoic acid aerosol particles, has no noticeable effect on the efflorescence point of AS in the mixed aerosol particles. Results 


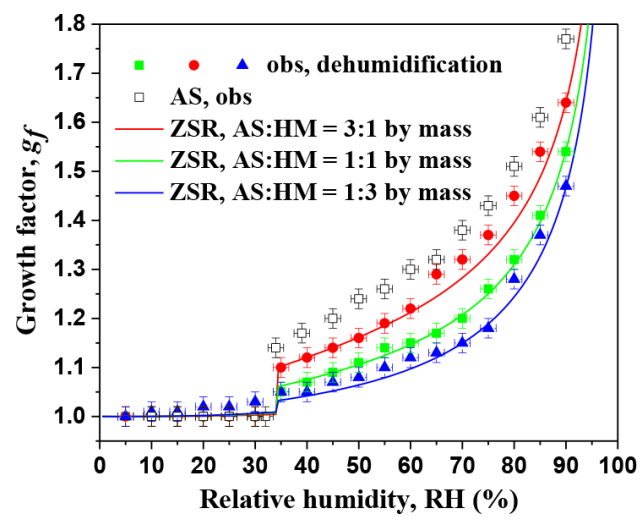

Figure 5. Hygroscopic growth factors and efflorescence of aerosol particles and constituents consisting of humic acid and ammonium sulfate at three different dry-state mass fractions with initial dry diameter of $100 \mathrm{~nm}$ at $\mathrm{RH}<5 \%$ as compared to that of pure ammonium sulfate (open symbols). Colored curves: ZSR predictions of diameter growth factors for dry particle compositions corresponding to the experimental data during dehumidification in the range from 90 to $5 \% \mathrm{RH}$ at $298.15 \mathrm{~K}$.

of the ZSR model agree well with measured hygroscopic growth for mixtures within the experimental error. The ZSR curves shown in Fig. 5 are based on the RH-dependent fitted HGFs of humic acid with Eq. (5) and the AIOMFACpredicted diameter growth factors of AS in the dehydration mode. The success of the ZSR mixing rule for this system suggests that interactions of organic molecules with AS ions in aqueous solution will only marginally affect the HGFs of the mixtures containing humic acid and AS. Due to the lack of detailed information about the actual chemical structures of humic acid samples used, it was not possible to perform EAIM and AIOMFAC model predictions for comparison with the measurement.

\subsection{Mixtures of biomass burning organic surrogate components with ammonium sulfate}

According to Decesari et al. (2006), sampling of aerosol particles, including the water-soluble organic carbon (WSOC) fraction, was conducted from 9 September to 14 November 2002 in their field study; the sampling time was subdivided into different periods. Despite significant changes in the chemical composition of tracer compounds from the dry to the wet period, the functional groups and general chemical classes of WSOC changed only to a small extent in the Amazon Basin near Rondônia, Brazil. Model compounds represent semiquantitatively (presence and abundance of functional groups) and the chemical structure of WSOC can be used as surrogates in microphysical models involving organic aerosol particles over tropical areas affected by biomass burning scenarios (Andreae et al., 2002; Artaxo et al., 2002; Rissler et al., 2006; Decesari et al., 2006). Here, we focus on experimental observations and model cal- culations for relatively simple mixtures of inorganic-organic surrogate components reflecting mixtures of aerosol components found during different seasons during biomass burning events. However, we are fully aware of the fact that actual biomass burning aerosols are typically much more complex in terms of particle chemical composition. Aerosol particle properties from biomass burning events depend on the type of source, external-internal population mixing state, watersolubilities, and phase state of the diversity of organic compounds and their mixing with inorganic constituents during different time periods in the field (e.g., Decesari et al., 2006).

\subsubsection{Mixture system: mix-bio-dry and mix-bio-wet aerosol particles}

Figure 6a shows the small differences observed in the hygroscopicity parameter $\kappa$ for mixtures of organic surrogate components and AS representing biomass burning particles during the dry and wet periods in the Amazon, respectively. Hygroscopicity parameter values for bio-mix-dry aerosol particles were determined to be between 0.16 and 0.18 , with a decreasing RH in the range from 90 to $40 \% \mathrm{RH}$. The $\kappa$ value representing the wet period in the Amazon is shown in Fig. 6b, derived from laboratory HTDMA measurements in the range from 90 to $40 \% \mathrm{RH}$. A similar trend of an increase in $\kappa$ with a decrease in RH has also been observed by Cheung et al. (2015). Their observation is based on ambient particle measurement with a HTDMA in Hong Kong, therefore probing particles of more complex compositions in the field campaign. The variability in the hygroscopicity parameter in subsaturated conditions reveals some limitations of a single-parameter hygroscopicity model for applications over a wide range of RH values. At low, intermediate, and high RH levels, differing degrees of solution nonideality, potential for liquid-liquid phase separation, water-solubility limitations of organics in ambient organic-inorganic particles, and assumptions about constant-variable surface tension may all play a role (Mikhailov et al., 2009; Rastak et al., 2017; Ovadnevaite et al., 2017). In the case of $\kappa$ of organic surrogates mixed with AS, the relevant $\kappa$ value range is $\sim 0.12$ to 0.15 obtained from 90 to $40 \%$ RH. The measured $\kappa$ values of the mixtures are compared to field data of HTDMA and CCN measurements conducted at a remote rainforest site in the central Amazon Basin during the dry and wet seasons (Whitehead et al., 2016; Pöhlker et al., 2016), which are consistent with $\kappa$ obtained at similar field sites (within the uncertainty of experiments). The likely reason for a relatively good agreement between the hygroscopicity of the laboratory mixtures and the field data is that the organic mass fractions of the mix-bio-dry and mix-bio-wet mixtures are chosen in our laboratory experiments to be similar to those of the latest field data from the Amazon Basin. For example, Pöhlker et al. (2016) obtained the effective hygroscopicity parameters $\kappa$ between $0.3 \pm 0.01$ and $0.15 \pm 0.01$ based on the organic mass fraction range from 0.65 to 0.97 in the dry season us- 

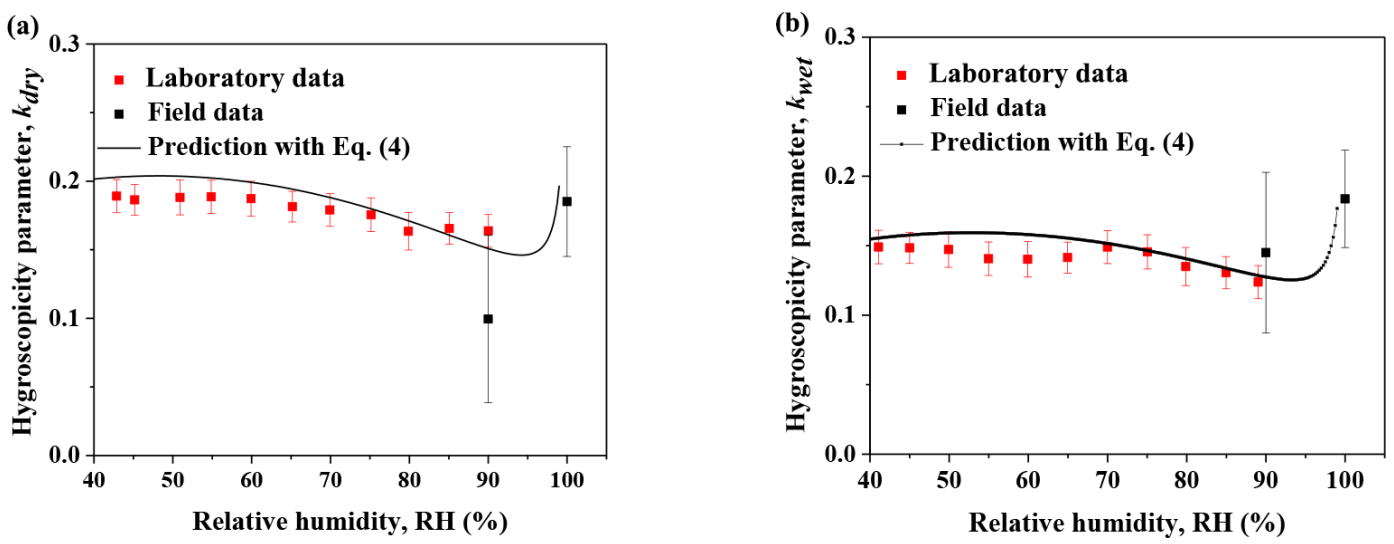

Figure 6. Hygroscopicity parameter, $\kappa$, representing mixed aerosol particles consisting of organic surrogate components and ammonium sulfate at different periods (initial dry diameter of $100 \mathrm{~nm}$ at $\mathrm{RH}<5 \%$ ). The black curves in both panels show the $\kappa$ prediction from Eq. (4) with $\mathrm{HGF}_{\text {mix }}$ calculated with Eq. (6) using component volume fractions and the HGF of the individual mixture components from a fit to the laboratory data (using Eq. 5). The black symbols and error bars show field data from the Amazon Basin during the dry and wet periods at conditions of water vapor subsaturation (HTDMA measurement) and supersaturation $\left(\kappa_{\mathrm{CNN}}\right)$ (Whitehead et al., 2016; Pöhlker et al., 2016).

ing aerosol chemical speciation monitor and CCN measurements. The predicted $\kappa$ values of the mixtures at various $\mathrm{RH}$ levels shown in Fig. 6 (black curves) are obtained through application of Eq. (4) with use of the RH-dependent fitted HGFs of the organic surrogates (Eq. 5), the predicted growth factor of AS from the AIOMFAC model (for the humidification case), and the mixing rule based on volume fraction for a mixture's HGF (Eq. 6). For these calculations, a solution surface tension of $0.072 \mathrm{~J} \mathrm{~m}^{-2}$ was assumed. These predictions agree relatively well with the experimental $\kappa_{\mathrm{dry}}$ and $\kappa_{\text {wet }}$ values obtained from the HTDMA over a wide range in $\mathrm{RH}$ values referring to dehumidification conditions (no solid AS). Furthermore, the combined approach of Eqs. (4)-(6) allows for a prediction of the change in $\kappa$ at high RH towards water vapor supersaturation. A small difference in $\kappa$ between sub- and supersaturated conditions is observed for our mixed systems when comparing the HTDMA data and predictions at $90 \% \mathrm{RH}$ with the predictions near $100 \% \mathrm{RH}$ and the $\kappa$ values from the $\mathrm{CNN}$ field measurements. The difference is more pronounced for the wet season case. Rastak et al. (2017) observed a marked difference in apparent hygroscopicity and related mixture $\kappa$ of the organic aerosols (ASfree) occurring in the case of monoterpene-derived secondary organic aerosol (SOA) for sub- vs. supersaturated conditions. A smaller difference was reported for the isoprene-derived SOA (Pajunoja et al., 2015: Rastak et al., 2017), more like the difference observed here for the mixtures containing AS (and therefore having overall higher $\kappa$ values than typical salt-free organic aerosols). Rastak et al. (2017) attribute the distinct difference in $\kappa_{\mathrm{SOA}}$ of the monoterpene SOA to the limited mutual solubility of certain SOA components in water because a single liquid organic phase of monoterpene oxidation products is present at RH below $95 \%$, but over a $\mathrm{RH}$ range above $95 \%$, liquid-liquid phase separation is observed using optical microscopy as well as predicted by the AIOMFAC-based equilibrium model. In the mix-biowet and mix-bio-dry cases shown in Fig. 6, the likely reason for the change in characteristic mixture hygroscopicity is not necessarily due to a liquid-liquid phase separation at high RH. For example, the $\kappa$ parameter obtained from field data is $\sim 0.15 \pm 0.06$ at $90 \% \mathrm{RH}$, while its value reaches $\sim 0.18 \pm 0.04$ at $\mathrm{RH}>100 \%$ (just prior to $\mathrm{CCN}$ activation). A likely reason for the difference is that hygroscopic particles, especially those containing sparingly soluble organics like 4-hydroxybenzoic acid, take up water dramatically above $95 \%$ RH when approaching $100 \%$ RH (Hartz et al., 2006; Chan et al., 2008; Rastak et al., 2017), which is clear from model predictions, as demonstrated in Fig. 6 by application of Eq. (4). The predicted curve in the mixture's effective $\kappa$ parameter may well capture the change in hygroscopicity under such high RH conditions. Consequently, for a precise representation of the hygroscopic growth behavior (e.g., HGF) at high RH (> $95 \%$ ) by the $\kappa$-Köhler model, the value of $\kappa$ would need to be varied. While a variable $\kappa$ value is contrary to the attempted simplicity of the single-parameter $\kappa$-Köhler model, it is at least advisable to consider that $\kappa$ values derived from HGF data at 80 or $90 \%$ RH may not apply accurately for the calculation of $\mathrm{CCN}$ activation properties of such biomass burning aerosols.

To summarize, there is small difference in hygroscopicity parameters between subsaturated measurement conditions at $90 \%$ RH in the laboratory with HTDMA and supersaturated conditions using $\mathrm{CCN}$ measurements, in agreement with the findings of other studies. On a regional scale, in the dry and wet periods, the hygroscopic behavior in some extent of the Amazon rainforest is influenced significantly by the biomass burning emissions, which enhances $\mathrm{CCN}$ activity and droplet number concentrations in warm clouds in that region and 
influences the radiation balance and cloud lifetime (Pöschl et al., 2010). Underestimation of organic surrogate component mass fractions in the mixed particles or organic: sulfate mass ratios may be responsible for the slight differences in the determined $\kappa$ parameters of the laboratory and field measurements.

\section{Conclusions}

A number of field-based hygroscopicity studies about biomass burning aerosol focus on the growth factors of mixtures at high RH (e.g., $90 \%$ RH). However, less attention has been paid to the growth behavior at low to moderate $\mathrm{RH}$, limiting the database for accurate estimates of particles' optical and radiative properties over those lower RH ranges. However, this is a RH range in which water uptake or release behavior demonstrates a considerable variability among different organic-inorganic systems. The occurrence or suppression of a liquid-solid phase transition affects the physicochemical particle properties in a relatively narrow RH range, potentially leading to particles of different morphology and physical states, affecting effective particle size and density. In this work, measurements and thermodynamic equilibrium predictions for organic-inorganic aerosols related to components from biomass burning emissions demonstrate a diversity of hygroscopic growth-shrinking behavior. For example, in the case of aerosol mixtures containing levoglucosan and AS, the presence of levoglucosan may cause the efflorescence of AS to occur at a higher RH than in pure aqueous AS particles, or it may completely suppress AS efflorescence, as observed for mixtures with a high levoglucosan mass fraction. The growth curves predicted with an AIOMFAC-based thermodynamic equilibrium model reproduce the observations in most cases reasonably well, and we demonstrate the usefulness of predictions with different assumptions about the physical state of the organic components for the interpretation of experimental data, such as in the case of mixtures of 4-hydroxybenzoic acid and AS. However, the accurate prediction of AS efflorescence or its suppression in mixed particles is difficult. The E-AIM-predicted growth curves reproduce the measured hygroscopic behavior relatively well for the consideration of the effect of 4-hydroxybenzoic acid on the hygroscopic behavior of mixtures with AS, which leads to suppression of the AS efflorescence. In the case of mixtures of humic acid and AS, continuous water desorption of aerosol particles shows no significant effect on the efflorescence of AS. Also, as expected, there is a clear reduction in the diameter growth factor of mixed systems, in comparison with that of pure AS particles. In addition, the small difference in hygroscopicity parameters of mix-bio-dry and mixbio-wet systems between measured data in the laboratory using HTDMA and in the field using $\mathrm{CCN}$ activity measurements is due to the similar $\mathrm{O}: \mathrm{C}$ ratios of organic surrogate compounds and AS mass fractions used in the model mix- tures when experimental $\kappa$ data from sub- and supersaturated water vapor conditions are compared.

The range of measurement-model comparisons presented in this study indicate that providing accurate thermodynamic model predictions of the hygroscopic growth behavior of mixed organic-inorganic systems remains a challenging problem. At moderate and low RH levels, at which aerosol solution phases become highly concentrated, step-like or gradual crystallization and related solid-liquid equilibria may occur with high sensitivity to the organic/inorganic mass ratio and the chemical nature of the mixture constituents. To further improve thermodynamic equilibrium models for the prediction of hygroscopicity and phase transitions, controlled laboratory experiments with single solutes and/or with mixed organic-inorganic systems of known phase state will be useful to constrain model parameters. Ideally, such measurements should cover the high, intermediate, and low RH ranges under humidification and dehumidification conditions.

Data availability. The measured results underlying this publication are available in the supplement.

\section{The Supplement related to this article is available online at https://doi.org/10.5194/acp-18-1045-2018-supplement.}

Competing interests. The authors declare that they have no conflict of interest.

Acknowledgements. This project was supported by the Strategic Priority Research Program (B) of the Chinese Academy of Sciences (grant no. XDB05010400), the National Key Research and Development Program of China (2016YFC0202202), and the National Natural Science Foundation of China (contract nos. 91544227, 41227805). The authors would like to thank Juan Hong and Zhibing Wang for comments and suggestions for the improvement of the paper.

Edited by: Markus Petters

Reviewed by: two anonymous referees

\section{References}

Altaf, M. B., Zuend, A., and Freedman, M. A.: Role of nucleation mechanism on the size dependent morphology of organic aerosol, Chem. Commun., 52, 9220-9223, 2016.

Andreae, M. O. and Gelencsér, A.: Black carbon or brown carbon? The nature of light-absorbing carbonaceous aerosols, Atmos. Chem. Phys., 6, 3131-3148, https://doi.org/10.5194/acp-63131-2006, 2006. 
Andreae, M. O., Artaxo, P., Brandao, C., Carswell, F. E., Ciccioli, P., da Costa, A. L., Culf, A. D., Esteves, J. L., Gash, J. H. C., Grace, J., Kabat, P., Lelieveld, J., Malhi, Y., Manzi, A. O., Meixner, F. X., Nobre, A. D., Nobre, C., Ruivo, M., Silva-Dias, M. A., Stefani, P., Valentini, R., von Jouanne, J., and Waterloo, M. J.: Biogeochemical cycling of carbon, water, energy, trace gases, and aerosols in Amazonia: The LBA-EUSTACH experiments, J. Geophys. Res., 107, 8066, https://doi.org/10.1029/2001JD000524, 2002.

Apelblat, A.: The vapour pressures of saturated aqueous solutions of potassium bromide, ammonium sulfate, copper(II) sulfate, iron(II) sulfate, and manganese(II) dichloride, at temperatures from 283 to 308 K, J. Chem. Thermodyn., 25, 1513-1520, 1993.

Arnold, S. R., Emmons, L. K., Monks, S. A., Law, K. S., Ridley, D. A., Turquety, S., Tilmes, S., Thomas, J. L., Bouarar, I., Flemming, J., Huijnen, V., Mao, J., Duncan, B. N., Steenrod, S., Yoshida, Y., Langner, J., and Long, Y.: Biomass burning influence on high-latitude tropospheric ozone and reactive nitrogen in summer 2008: a multi-model analysis based on POLMIP simulations, Atmos. Chem. Phys., 15, 6047-6068, https://doi.org/10.5194/acp-15-6047-2015, 2015.

Artaxo, P., Martins, J. V., Yamasoe, M. A., Procópio, A. S., Pauliquevis, T. M., Andreae, M. O., Guyon, P., Gatti, L. V., and Leal, A. M. C.: Physical and chemical properties of aerosols in the wet and dry seasons in Rondônia, Amazonia, J. Geophys. Res., 107, 8081, https://doi.org/10.1029/2001JD000666, 2002.

Atkinson, D. B., Radney, J. G., Lum, J., Kolesar, K. R., Cziczo, D. J., Pekour, M. S., Zhang, Q., Setyan, A., Zelenyuk, A., and Cappa, C. D.: Aerosol optical hygroscopicity measurements during the 2010 CARES campaign, Atmos. Chem. Phys., 15, 40454061, https://doi.org/10.5194/acp-15-4045-2015, 2015.

Bodsworth, A., Zobrist, B., and Bertram, A. K.: Inhibition of efflorescence in mixed organic-inorganic particles at temperatures less than 250 K, Phys. Chem. Chem. Phys., 12, 12259-12266, 2010.

Bones, D. L., Reid, J. P., Lienhard, D. M., and Krieger, U. K.: Comparing the mechanism of water condensation and evaporation in glassy aerosol, P. Natl. Acad. Sci. USA, 109, 11613-11618, 2012.

Boucher Olivier and David, R.: Clouds and Aerosols, Intergovernmental Panel on Climate Change, 2014, Climate Change 2013 - The Physical Science Basis: Working Group I Contribution to the Fifth Assessment Report of the Intergovernmental Panel on Climate Change, Cambridge University Press, Cambridge, https://doi.org/10.1017/CBO9781107415324, 2013.

Brooks, S. D., DeMott, P. J., and Kreidenweis, S. M.: Water uptake by particles containing humic materials and mixtures of humic materials with ammonium sulfate, Atmos. Environ., 38, 18591868, 2004.

Carrico, C. M., Petters, M. D., Kreidenweis, S. M., Collett, J. L., Engling, G., and Malm, W. C.: Aerosol hygroscopicity and cloud droplet activation of extracts of filters from biomass burning experiments, J. Geophys. Res., 113, D08206, https://doi.org/10.1029/2007JD009274, 2008.

Chan, M. N. and Chan, C. K.: Hygroscopic properties of two model humic-like substances and their mixtures with inorganics of atmospheric importance, Environ. Sci. Technol., 37, 5109-5115, 2003.
Chan, M. N. and Chan, C. K.: Mass transfer effects in hygroscopic measurements of aerosol particles, Atmos. Chem. Phys. 5, 2703-2712, https://doi.org/10.5194/acp-5-2703-2005, 2005.

Chan, M. N., Choi, M. Y., Ng, N. L., and Chan, C. K.: Hygroscopicity of water-soluble organic compounds in atmospheric aerosols: amino acids and biomass burning derived organic species, Environ. Sci. Technol., 39, 1555-1562, 2005.

Chan, M. N., Kreidenweis, S. M., and Chan, C. K.: Measurements of the hygroscopic and deliquescence properties of organic compounds of different solubilities in water and their relationship with cloud condensation nuclei activities, Environ. Sci. Technol., 42, 3602-3608, 2008.

Cheng, Y. F., Su, H., Rose, D., Gunthe, S. S., Berghof, M., Wehner, B., Achtert, P., Nowak, A., Takegawa, N., Kondo, Y., Shiraiwa, M., Gong, Y. G., Shao, M., Hu, M., Zhu, T., Zhang, Y. H., Carmichael, G. R., Wiedensohler, A., Andreae, M. O., and Pöschl, U.: Size-resolved measurement of the mixing state of soot in the megacity Beijing, China: diurnal cycle, aging and parameterization, Atmos. Chem. Phys., 12, 4477-4491, https://doi.org/10.5194/acp-12-4477-2012, 2012.

Cheung, H. H. Y., Yeung, M. C., Li, Y. J., Lee, B. P., and Chan, C. K.: Relative humidity-dependent HTDMA measurements of ambient aerosols at the HKUST supersite in Hong Kong, China, Aerosol Sci. Tech., 49, 643-654, 2015.

Choi, M. Y. and Chan, C. K.: The effects of organic species on the hygroscopic behaviors of inorganic aerosols, Environ. Sci. Technol., 36, 2422-2428, 2002.

Ciobanu, V. G., Marcolli, C., Krieger, U. K., Zuend, A., and Peter, T.: Efflorescence of ammonium sulfate and coated ammonium sulfate particles: evidence for surface nucleation, J. Phys. Chem. A, 114, 9486-9495, 2010.

Clegg, S. L. and Seinfeld, J. H.: Thermodynamic models of aqueous solutions containing inorganic electrolytes and dicarboxylic acids at 298.15 K. 2. Systems including dissociation equilibria, J. Phys. Chem. A, 110, 5718-5734, 2006.

Clegg, S. L. and Wexler, A. S.: Densities and apparent molar volumes of atmospherically important electrolyte solutions, 1. The solutes $\mathrm{H}_{2} \mathrm{SO}_{4}, \mathrm{HNO}_{3}, \mathrm{HCl}, \mathrm{Na}_{2} \mathrm{SO}_{4}, \mathrm{NaNO}_{3}, \mathrm{NaCl}$, $\left(\mathrm{NH}_{4}\right)(2) \mathrm{SO}_{4}, \mathrm{NH}_{4} \mathrm{NO}_{3}$, and $\mathrm{NH} 4 \mathrm{Cl}$ from 0 to $50^{\circ} \mathrm{C}$, including extrapolations to very low temperature and to the pure liquid state, and $\mathrm{NaHSO}_{4}, \mathrm{NaOH}$, and $\mathrm{NH}_{3}$ at $25^{\circ} \mathrm{C}$, J. Phys. Chem. A, 115, 3393-3460, 2011a.

Clegg, S. L. and Wexler, A. S.: Densities and apparent molar volumes of atmospherically important electrolyte solutions, 2. The systems $\mathrm{H}^{(+)}-\mathrm{HSO}_{4}^{(-)}-\mathrm{SO}_{4}^{(2-)}-\mathrm{H}_{2} \mathrm{O}$ from 0 to $3 \mathrm{~mol} \mathrm{~kg}^{(-1)}$ as a function of temperature and $\mathrm{H}^{(+)}-\mathrm{NH}_{4}^{(+)}-\mathrm{HSO}_{4}^{(-)}-\mathrm{SO}_{4}^{(2-)}-\mathrm{H}_{2} \mathrm{O}$ from 0 to $6 \mathrm{~mol} \mathrm{~kg}(-1)$ at $25^{\circ} \mathrm{C}$ using a Pitzer ion interaction model, and $\mathrm{NH}_{4} \mathrm{HSO}_{4}-\mathrm{H} 2 \mathrm{O}$ and $\left(\mathrm{NH}_{4}\right)_{3} \mathrm{H}\left(\mathrm{SO}_{4}\right)_{2}-\mathrm{H}_{2} \mathrm{O}$ over the entire concentration range, J. Phys. Chem. A, 115, 3461-3474, 2011b.

Clegg, S. L., Brimblecombe, P., and Wexler, A. S.: Thermodynamic Model of the System $\mathrm{H}^{+}-\mathrm{NH}_{4}^{+}-\mathrm{SO}_{4}^{2-}-\mathrm{NO}_{3}^{-}-\mathrm{H}_{2} \mathrm{O}$ at Tropospheric Temperatures, J. Phys. Chem. A, 102, 2137-2154, 1998.

Decesari, S., Fuzzi, S., Facchini, M. C., Mircea, M., Emblico, L., Cavalli, F., Maenhaut, W., Chi, X., Schkolnik, G., Falkovich, A., Rudich, Y., Claeys, M., Pashynska, V., Vas, G., Kourtchev, I., Vermeylen, R., Hoffer, A., Andreae, M. O., Tagliavini, 
E., Moretti, F., and Artaxo, P.: Characterization of the organic composition of aerosols from Rondônia, Brazil, during the LBA-SMOCC 2002 experiment and its representation through model compounds, Atmos. Chem. Phys., 6, 375-402, https://doi.org/10.5194/acp-6-375-2006, 2006.

Denjean, C., Formenti, P., Picquet-Varrault, B., Pangui, E., Zapf, P., Katrib, Y., Giorio, C., Tapparo, A., Monod, A., Temime-Roussel, B., Decorse, P., Mangeney, C., and Doussin, J. F.: Relating hygroscopicity and optical properties to chemical composition and structure of secondary organic aerosol particles generated from the ozonolysis of $\alpha$-pinene, Atmos. Chem. Phys., 15, 3339-3358, https://doi.org/10.5194/acp-15-3339-2015, 2015.

Dusek, U., Frank, G. P., Massling, A., Zeromskiene, K., Iinuma, Y., Schmid, O., Helas, G., Hennig, T., Wiedensohler, A., and Andreae, M. O.: Water uptake by biomass burning aerosol at suband supersaturated conditions: closure studies and implications for the role of organics, Atmos. Chem. Phys., 11, 9519-9532, https://doi.org/10.5194/acp-11-9519-2011, 2011.

Engelhart, G. J., Hennigan, C. J., Miracolo, M. A., Robinson, A. L., and Pandis, S. N.: Cloud condensation nuclei activity of fresh primary and aged biomass burning aerosol, Atmos. Chem. Phys., 12, 7285-7293, https://doi.org/10.5194/acp12-7285-2012, 2012.

Favez, O., Alfaro, S. C., Sciare, J., Cachier, H., and Abdelwahab, M. M.: Ambient measurements of light-absorption by agricultural waste burning organic aerosols, J. Aerosol Sci., 40, 613620, 2009

Fredenslund, A., Jones, R. L., and Prausnitz, J. M.: A groupcontribution method is presented for the prediction of activity coefficients in nonelectrolyte liquid mixtures, Aiche J., 21, 10861099, 1975 .

Gilman, J. B., Lerner, B. M., Kuster, W. C., Goldan, P. D., Warneke, C., Veres, P. R., Roberts, J. M., de Gouw, J. A., Burling, I. R., and Yokelson, R. J.: Biomass burning emissions and potential air quality impacts of volatile organic compounds and other trace gases from fuels common in the US, Atmos. Chem. Phys., 15, 13915-13938, https://doi.org/10.5194/acp-15-139152015, 2015.

Gupta, D., Eom, H.-J., Cho, H.-R., and Ro, C.-U.: Hygroscopic behavior of $\mathrm{NaCl}-\mathrm{MgCl}_{2}$ mixture particles as nascent seaspray aerosol surrogates and observation of efflorescence during humidification, Atmos. Chem. Phys., 15, 11273-11290, https://doi.org/10.5194/acp-15-11273-2015, 2015.

Hansen, H. K., Rasmussen, P., Fredenslund, A., Schiller, M., and Gmehling, J.: Vapor-liquid equilibria by UNIFAC group contribution. 5. Revision and extension, Ind. Eng. Chem. Res., 30, 2352-2355, 1991.

Hartz, K. E. H., Tischuk, J. E., Chan, M. N., Chan, C. K., Donahue, N. M., and Pandis, S. N.: Cloud condensation nuclei activation of limited solubility organic aerosol, Atmos. Environ., 40, 605-617, 2006.

Hecobian, A., Zhang, X., Zheng, M., Frank, N., Edgerton, E. S., and Weber, R. J.: Water-Soluble Organic Aerosol material and the light-absorption characteristics of aqueous extracts measured over the Southeastern United States, Atmos. Chem. Phys., 10, 5965-5977, https://doi.org/10.5194/acp-10-5965-2010, 2010.

Hegg, D. A., Warren, S. G., Grenfell, T. C., Sarah J Doherty, and Clarke, A. D.: Sources of light-absorbing aerosol in arctic snow and their seasonal variation, Atmos. Chem. Phys., 10, 10923 10938, https://doi.org/10.5194/acp-10-10923-2010, 2010.

Hodas, N., Zuend, A., Mui, W., Flagan, R. C., and Seinfeld, J. H.: Influence of particle-phase state on the hygroscopic behavior of mixed organic-inorganic aerosols, Atmos. Chem. Phys., 15, 5027-5045, https://doi.org/10.5194/acp-15-5027-2015, 2015.

Hodas, N., Zuend, A., Schilling, K., Berkemeier, T., Shiraiwa, M., Flagan, R. C., and Seinfeld, J. H.: Discontinuities in hygroscopic growth below and above water saturation for laboratory surrogates of oligomers in organic atmospheric aerosols, Atmos. Chem. Phys., 16, 12767-12792, https://doi.org/10.5194/acp-1612767-2016, 2016.

Jacobson, M. Z.: Effects of biomass burning on climate, accounting for heat and moisture fluxes, black and brown carbon, and cloud absorption effects, J. Geophys. Res.-Atmos., 119, 89809002, 2014.

Jedelský, J., Hnědkovský, L., Hynčica, P., and Cibulka, I.: Partial molar volumes of organic solutes in water. IV. Benzoic and hydroxybenzoic acids at temperatures from $\mathrm{T}=298 \mathrm{~K}$ to $\mathrm{T}=498 \mathrm{~K}$ and pressures up to $30 \mathrm{MPa}$, J. Chem. Thermodyn., 32, 12991310, 2000.

Jing, B., Tong, S., Liu, Q., Li, K., Wang, W., Zhang, Y., and Ge, M.: Hygroscopic behavior of multicomponent organic aerosols and their internal mixtures with ammonium sulfate, Atmos. Chem. Phys., 16, 4101-4118, https://doi.org/10.5194/acp-164101-2016, 2016.

Kerminen, V. M.: The effects of particle chemical character and atmospheric processes on particle hygroscopic properties, J. Aerosol Sci., 28, 121-132, 1997.

Kim, J., Ahlm, L., Yli-Juuti, T., Lawler, M., Keskinen, H., Tröstl, J., Schobesberger, S., Duplissy, J., Amorim, A., Bianchi, F., Donahue, N. M., Flagan, R. C., Hakala, J., Heinritzi, M., Jokinen, T., Kürten, A., Laaksonen, A., Lehtipalo, K., Miettinen, P., Petäjä, T., Rissanen, M. P., Rondo, L., Sengupta, K., Simon, M., Tomé, A., Williamson, C., Wimmer, D., Winkler, P. M., Ehrhart, S., Ye, P., Kirkby, J., Curtius, J., Baltensperger, U., Kulmala, M., Lehtinen, K. E. J., Smith, J. N., Riipinen, I., and Virtanen, A.: Hygroscopicity of nanoparticles produced from homogeneous nucleation in the CLOUD experiments, Atmos. Chem. Phys., 16 , 293-304, https://doi.org/10.5194/acp-16-293-2016, 2016.

Kiss, G., Tombácz, E., and Hansson, H.-C.: Surface tension effects of humic-like substances in the aqueous extract of tropospheric fine aerosol, J. Atmos. Chem., 50, 279-294, 2005.

Koop, T., Bookhold, J., Shiraiwa, M., and Poschl, U.: Glass transition and phase state of organic compounds: dependency on molecular properties and implications for secondary organic aerosols in the atmosphere, Phys. Chem. Chem. Phys., 13, 19238-19255, 2011.

Laborde, M., Crippa, M., Tritscher, T., Jurányi, Z., Decarlo, P. F., Temime-Roussel, B., Marchand, N., Eckhardt, S., Stohl, A., Baltensperger, U., Prévôt, A. S. H., Weingartner, E., and Gysel, M.: Black carbon physical properties and mixing state in the European megacity Paris, Atmos. Chem. Phys., 13, 5831-5856, https://doi.org/10.5194/acp-13-5831-2013, 2013.

Lack, D. A., Langridge, J. M., Bahreini, R., Cappa, C. D., Middlebrook, A. M., and Schwarz, J. P.: Brown carbon and internal mixing in biomass burning particles, P. Natl. Acad. Sci. USA, 109, 14802-14807, 2012. 
Lawson, S. J., Keywood, M. D., Galbally, I. E., Gras, J. L., Cainey, J. M., Cope, M. E., Krummel, P. B., Fraser, P. J., Steele, L. P., Bentley, S. T., Meyer, C. P., Ristovski, Z., and Goldstein, A. H.: Biomass burning emissions of trace gases and particles in marine air at Cape Grim, Tasmania, Atmos. Chem. Phys., 15, 1339313411, https://doi.org/10.5194/acp-15-13393-2015, 2015.

Lee, Y. N.: Airborne measurement of inorganic ionic components of fine aerosol particles using the particle-intoliquid sampler coupled to ion chromatography technique during ACE-Asia and TRACE-P, J. Geophys. Res., 108, 8646, https://doi.org/10.1029/2002JD003265, 2003.

Lei, T., Zuend, A., Wang, W. G., Zhang, Y. H., and Ge, M. F.: Hygroscopicity of organic compounds from biomass burning and their influence on the water uptake of mixed organic ammonium sulfate aerosols, Atmos. Chem. Phys., 14, 11165-11183, https://doi.org/10.5194/acp-14-11165-2014, 2014.

Lienhard, D. M., Bones, D. L., Zuend, A., Krieger, U. K., Reid, J. P., and Peter, T.: Measurements of thermodynamic and optical properties of selected aqueous organic and organic-inorganic mixtures of atmospheric relevance, J. Phys. Chem. A, 116, 99549968, 2012.

Liu, B. Y., Pui, D. Y., and Rubow, K. L., and Szymanski, W. W.: Electrostatic effects in aerosol sampling and filtration, Ann. Occup. Hyg., 29, 251-269, 1985.

Liu, J. M., Scheuer, E., Dibb, J., Ziemba, L. D., Thornhill, K. L., Anderson, B. E., Wisthaler, A., Mikoviny, T., Devi, J. J., Bergin, M., and Weber, R. J.: Brown carbon in the continental troposphere, Geophys. Res. Lett., 41, 2191-2195, 2014.

Liu, Q., Jing, B., Peng, C., Tong, S., Wang, W., and Ge, M.: Hygroscopicity of internally mixed multi-component aerosol particles of atmospheric relevance, Atmos. Environ., 125, 69-77, 2016.

Malm, W. C. and Kreidenweis, S. M.: The effects of models of aerosol hygroscopicity on the apportionment of extinction, Atmos. Environ., 31, 1965-1976, 1997.

Marcolli, C. and Peter, Th.: Water activity in polyol/water systems: new UNIFAC parameterization, Atmos. Chem. Phys., 5, 15451555, https://doi.org/10.5194/acp-5-1545-2005, 2005.

Marshall, F. H., Miles, R. E. H., Song, Y.-C., Ohm, P. B., Power, R. M., Reid, J. P., and Dutcher, C. S.: Diffusion and reactivity in ultraviscous aerosol and the correlation with particle viscosity, Chem. Sci., 7, 1298-1308, 2016.

Martin, M., Tritscher, T., Juranyi, Z., Heringa, M. F., Sierau, B., Weingartner, E., Chirico, R., Gysel, M., Prevot, A. S. H., Baltensperger, U., and Lohmann, U.: Hygroscopic properties of fresh and aged wood burning particles, J. Aerosol Sci., 56, 1529, 2013.

Mikhailov, E., Vlasenko, S., Niessner, R., and Pöschl, U.: Interaction of aerosol particles composed of protein and saltswith water vapor: hygroscopic growth and microstructural rearrangement, Atmos. Chem. Phys., 4, 323-350, https://doi.org/10.5194/acp-4323-2004, 2004.

Mikhailov, E. F., Vlasenko, S. S., and Ryshkevich, T. I.: Influence of chemical composition and microstructure on the hygroscopic growth of pyrogenic aerosol, Izv. Atmos. Ocean. Phy., 44, 416431, 2008.

Mikhailov, E., Vlasenko, S., Martin, S. T., Koop, T., and Pöschl, U.: Amorphous and crystalline aerosol particles interacting with water vapor: conceptual framework and experimental evidence for restructuring, phase transitions and kinetic limitations, Atmos.
Chem. Phys., 9, 9491-9522, https://doi.org/10.5194/acp-9-94912009, 2009.

Mikhailov, E., Vlasenko, S., Rose, D., and Pöschl, U.: Mass-based hygroscopicity parameter interaction model and measurement of atmospheric aerosol water uptake, Atmos. Chem. Phys., 13, 717740, https://doi.org/10.5194/acp-13-717-2013, 2013.

Mochida, M. and Kawamura, K.: Hygroscopic properties of levoglucosan and related organic compounds characteristic to biomass burning aerosol particles, J. Geophys. Res., 109, D21202, https://doi.org/10.1029/2004JD004962, 2004.

Moosmuller, H., Chakrabarty, R. K., and Arnott, W. P.: Aerosol light absorption and its measurement: a review, J. Quant. Spectrosc. Ra., 110, 844-878, 2009.

Ovadnevaite, J., Zuend, A., Laaksonen, A., Sanchez, K. J., Roberts, G., Ceburnis, D., Decesari, S., Rinaldi, M., Hodas, N., Facchini, M. C., Seinfeld, J. H., and O'Dowd, C.: Surface tension prevails over solute effect in organicinfluenced cloud droplet activation, Nature, 546, 637-641, https://doi.org/10.1038/nature22806, 2017.

Paglione, M., Saarikoski, S., Carbone, S., Hillamo, R., Facchini, M. C., Finessi, E., Giulianelli, L., Carbone, C., Fuzzi, S., Moretti, F., Tagliavini, E., Swietlicki, E., Eriksson Stenström, K., Prévôt, A. S. H., Massoli, P., Canaragatna, M., Worsnop, D., and Decesari, S.: Primary and secondary biomass burning aerosols determined by proton nuclear magnetic resonance $\left({ }^{1} \mathrm{H}-\mathrm{NMR}\right)$ spectroscopy during the 2008 EUCAARI campaign in the Po Valley (Italy), Atmos. Chem. Phys., 14, 5089-5110, https://doi.org/10.5194/acp14-5089-2014, 2014.

Pajunoja, A., Lambe, A. T., Hakala, J., Rastak, N., Cummings, M. J., Brogan, J. F., Hao, L., Paramonov, M., Hong, J., Prisle, N. L., Malila, J., Romakkaniemi, S., Lehtinen, K. E. J., Laaksonen, A., Kulmala, M., Massoli, P., Onasch, T. B., Donahue, N. M., Riipinen, I., Davidovits, P., Worsnop, D. R., Petäjä, T., and Virtanen, A.: Adsorptive uptake of water by semisolid secondary organic aerosols, Geophys. Res. Lett., 42, 3063-3068, https://doi.org/10.1002/2015GL063142, 2015.

Peng, C., Chan, M. N., and Chan, C. K.: The hygroscopic properties of dicarboxylic and multifunctional acids: measurements and UNIFAC predictions, Environ. Sci. Technol., 35, 4495-4501, 2001.

Petters, M. D. and Kreidenweis, S. M.: A single parameter representation of hygroscopic growth and cloud condensation nucleus activity, Atmos. Chem. Phys., 7, 1961-1971, https://doi.org/10.5194/acp-7-1961-2007, 2007.

Pöhlker, M. L., Pöhlker, C., Ditas, F., Klimach, T., Hrabe de Angelis, I., Araújo, A., Brito, J., Carbone, S., Cheng, Y., Chi, X., Ditz, R., Gunthe, S. S., Kesselmeier, J., Könemann, T., Lavrič, J. V., Martin, S. T., Mikhailov, E., Moran-Zuloaga, D., Rose, D., Saturno, J., Su, H., Thalman, R., Walter, D., Wang, J., Wolff, S., Barbosa, H. M. J., Artaxo, P., Andreae, M. O., and Pöschl, U.: Longterm observations of cloud condensation nuclei in the Amazon rain forest - Part 1: Aerosol size distribution, hygroscopicity, and new model parametrizations for $\mathrm{CCN}$ prediction, Atmos. Chem. Phys., 16, 15709-15740, https://doi.org/10.5194/acp-16-157092016, 2016.

Pöschl, U., Martin, S. T., Sinha, B., Chen, Q., Gunthe, S. S., Huffman, J. A., Borrmann, S., Farmer, D. K., Garland, R. M., Helas, G., Jimenez, J. L., King, S. M., Manzi, A., Mikhailov, E., Pauliquevis, T., Petters, M. D., Prenni, A. J., Roldin, P., Rose, 
D., Schneider, J., Su, H., Zorn, S. R., Artaxo, P., and Andreae, M. O.: Rainforest Aerosols as Biogenic Nuclei of Clouds and Precipitation in the Amazon, Science, 329, 1513-1516, 2010.

Powelson, M. H., Espelien, B. M., Hawkins, L. N., Galloway, M. M., and De Haan, D. O.: Brown carbon formation by aqueous-phase carbonyl compound reactions with amines and ammonium sulfate, Environ. Sci. Technol., 48, 985-993, 2014.

Pratt, K. A. and Prather, K. A.: Aircraft measurements of vertical profiles of aerosol mixing states, J. Geophys. Res.,115, D11305, https://doi.org/10.1029/2009JD013150, 2010.

Pratt, K. A., Murphy, S. M., Subramanian, R., DeMott, P. J., Kok, G. L., Campos, T., Rogers, D. C., Prenni, A. J., Heymsfield, A. J., Seinfeld, J. H., and Prather, K. A.: Flight-based chemical characterization of biomass burning aerosols within two prescribed burn smoke plumes, Atmos. Chem. Phys., 11, 1254912565, https://doi.org/10.5194/acp-11-12549-2011, 2011.

Rastak, N., Pajunoja, A., Acosta Navarro, J. C., Ma, J., Song, M., Partridge, D. G., Kirkevåg, A., Leong, Y., Hu, W. W., Taylor, N. F., Lambe, A., Cerully, K., Bougiatioti, A., Liu, P., Krejci, R., Petäjä, T., Percival, C., Davidovits, P., Worsnop, D. R., Ekman, A. M. L., Nenes, A., Martin, S., Jimenez, J. L., Collins, D. R., Topping, D. O., Bertram, A. K., Zuend, A., Virtanen, A., and Riipinen, I.: Microphysical explanation of the $\mathrm{RH}$-dependent water affinity of biogenic organic aerosol and its importance for climate, Geophys. Res. Lett., 44, 5167-5177, https://doi.org/10.1002/2017GL073056, 2017.

Reid, J. P., Dennis-Smither, B. J., Kwamena, N.-O. A., Miles, R. E. H., Hanford, K. L., and Homer, C. J.: The morphology of aerosol particles consisting of hydrophobic and hydrophilic phases: hydrocarbons, alcohols and fatty acids as the hydrophobic component, Phys. Chem. Chem. Phys., 13, 1555915572, 2011.

Renbaum-Wolff, L., Song, M., Marcolli, C., Zhang, Y., Liu, P. F., Grayson, J. W., Geiger, F. M., Martin, S. T., and Bertram, A. K.: Observations and implications of liquid-liquid phase separation at high relative humidities in secondary organic material produced by $\alpha$-pinene ozonolysis without inorganic salts, Atmos. Chem. Phys., 16, 7969-7979, https://doi.org/10.5194/acp16-7969-2016, 2016.

Rissler, J., Vestin, A., Swietlicki, E., Fisch, G., Zhou, J., Artaxo, P., and Andreae, M. O.: Size distribution and hygroscopic properties of aerosol particles from dry-season biomass burning in Amazonia, Atmos. Chem. Phys., 6, 471-491, https://doi.org/10.5194/acp-6-471-2006, 2006.

Rizzo, L. V., Correia, A. L., Artaxo, P., Procópio, A. S., and Andreae, M. O.: Spectral dependence of aerosol light absorption over the Amazon Basin, Atmos. Chem. Phys., 11, 8899-8912, https://doi.org/10.5194/acp-11-8899-2011, 2011.

Rose, D., Gunthe, S. S., Su, H., Garland, R. M., Yang, H., Berghof, M., Cheng, Y. F., Wehner, B., Achtert, P., Nowak, A., Wiedensohler, A., Takegawa, N., Kondo, Y., Hu, M., Zhang, Y., Andreae, M. O., and Pöschl, U.: Cloud condensation nuclei in polluted air and biomass burning smoke near the megacity Guangzhou, China - Part 2: Size-resolved aerosol chemical composition, diurnal cycles, and externally mixed weakly CCN-active soot particles, Atmos. Chem. Phys., 11, 2817-2836, https://doi.org/10.5194/acp-11-2817-2011, 2011.

Saarnio, K., Aurela, M., Timonen, H., Saarikoski, S., Teinila, K., Makela, T., Sofiev, M., Koskinen, J., Aalto, P. P., Kulmala, M.,
Kukkonen, J., and Hillamo, R.: Chemical composition of fine particles in fresh smoke plumes from boreal wild-land fires in Europe, Sci. Total Environ., 408, 2527-2542, 2010.

Sadezky, A., Muckenhuber, H., Grothe, H., Niessner, R., and Poschl, U.: Raman micro spectroscopy of soot and related carbonaceous materials: spectral analysis and structural information, Carbon, 43, 1731-1742, 2005.

Saleh, R., Hennigan, C. J., McMeeking, G. R., Chuang, W. K., Robinson, E. S., Coe, H., Donahue, N. M., and Robinson, A. L.: Absorptivity of brown carbon in fresh and photo-chemically aged biomass-burning emissions, Atmos. Chem. Phys., 13, 7683 7693, https://doi.org/10.5194/acp-13-7683-2013, 2013.

Saleh, R., Robinson, E. S., Tkacik, D. S., Ahern, A. T., Liu, S., Aiken, A. C., Sullivan, R. C., Presto, A. A., Dubey, M. K., Yokelson, R. J., Donahue, N. M., and Robinson, A. L.: Brownness of organics in aerosols from biomass burning linked to their black carbon content, Nat. Geosci., 7, 647-650, 2014.

Seinfeld, J. and Pandis, S.: Atmospheric Chemistry and Physics, Wiley, Hoboken, NJ, 2006.

Shiraiwa, M., Zuend, A., Bertram, A. K., and Seinfeld, J. H.: Gasparticle partitioning of atmospheric aerosols: interplay of physical state, non-ideal mixing and morphology, Phys. Chem. Chem. Phys., 15, 11441-11453, 2013.

Sjogren, S., Gysel, M., Weingartner, E., Baltensperger, U., Cubison, M. J., Coe, H., Zardini, A. A., Marcolli, C., Krieger, U. K., and Peter, T.: Hygroscopic growth and water uptake kinetics of two-phase aerosol particles consisting of ammonium sulfate, adipic and humic acid mixtures, J. Aerosol Sci., 38, 157-171, 2007.

Smith, M. L., Bertram, A. K., and Martin, S. T.: Deliquescence, efflorescence, and phase miscibility of mixed particles of ammonium sulfate and isoprene-derived secondary organic material, Atmos. Chem. Phys., 12, 9613-9628, https://doi.org/10.5194/acp-12-9613-2012, 2012.

Song, M., Marcolli, C., Krieger, U. K., Zuend, A., and Peter, T.: Liquid-liquid phase separation and morphology of internally mixed dicarboxylic acids/ammonium sulfate/water particles, Atmos. Chem. Phys., 12, 2691-2712, https://doi.org/10.5194/acp12-2691-2012, 2012.

Song, M., Marcolli, C., Krieger, U. K., Zuend, A., and Peter, T.: Liquid-liquid phase separation in aerosol particles: dependence on $\mathrm{O}: \mathrm{C}$, organic functionalities, and compositional complexity, Geophys. Res. Lett., 39, L19801, https://doi.org/10.1029/2012GL052807, 2012.

Srinivas, B. and Sarin, M. M.: Light absorbing organic aerosols (brown carbon) over the tropical Indian Ocean: impact of biomass burning emissions, Environ. Res. Lett., 8, 044042, https://doi.org/10.1088/1748-9326/8/4/044042, 2013.

Srinivas, B. and Sarin, M. M.: Brown carbon in atmospheric outflow from the Indo-Gangetic Plain: mass absorption efficiency and temporal variability, Atmos. Environ., 89, 835-843, 2014.

Svenningsson, B., Rissler, J., Swietlicki, E., Mircea, M., Bilde, M., Facchini, M. C., Decesari, S., Fuzzi, S., Zhou, J., Mønster, J., and Rosenørn, T.: Hygroscopic growth and critical supersaturations for mixed aerosol particles of inorganic and organic compounds of atmospheric relevance, Atmos. Chem. Phys., 6, 1937-1952, https://doi.org/10.5194/acp-6-1937-2006, 2006.

Topping, D. O., McFiggans, G. B., and Coe, H.: A curved multicomponent aerosol hygroscopicity model framework: Part 1 
- Inorganic compounds, Atmos. Chem. Phys., 5, 1205-1222, https://doi.org/10.5194/acp-5-1205-2005, 2005.

Tuckermann, R. and Cammenga, H. K.: The surface tension of aqueous solutions of some atmospheric water-soluble organic compounds, Atmos. Environ., 38, 6135-6138, 2004.

Väkevä, M., Kulmala, M., Stratmann, F., and Hämeri, K.: Field measurements of hygroscopic properties and state of mixing of nucleation mode particles, Atmos. Chem. Phys., 2, 55-66, https://doi.org/10.5194/acp-2-55-2002, 2002.

Wang, J., Cubison, M. J., Aiken, A. C., Jimenez, J. L., and Collins, D. R.: The importance of aerosol mixing state and size-resolved composition on $\mathrm{CCN}$ concentration and the variation of the importance with atmospheric aging of aerosols, Atmos. Chem. Phys., 10, 7267-7283, https://doi.org/10.5194/acp10-7267-2010, 2010.

Wang, X., Heald, C. L., Ridley, D. A., Schwarz, J. P., Spackman, J. R., Perring, A. E., Coe, H., Liu, D., and Clarke, A. D.: Exploiting simultaneous observational constraints on mass and absorption to estimate the global direct radiative forcing of black carbon and brown carbon, Atmos. Chem. Phys., 14, 10989-11010, https://doi.org/10.5194/acp-14-10989-2014, 2014.

Whitehead, J. D., Darbyshire, E., Brito, J., Barbosa, H. M. J., Crawford, I., Stern, R., Gallagher, M. W., Kaye, P. H., Allan, J. D., Coe, H., Artaxo, P., and McFiggans, G.: Biogenic cloud nuclei in the central Amazon during the transition from wet to dry season, Atmos. Chem. Phys., 16, 9727-9743, https://doi.org/10.5194/acp-16-9727-2016, 2016.

Wu, Z. J., Zheng, J., Shang, D. J., Du, Z. F., Wu, Y. S., Zeng, L. M., Wiedensohler, A., and Hu, M.: Particle hygroscopicity and its link to chemical composition in the urban atmosphere of Beijing, China, during summertime, Atmos. Chem. Phys., 16, 11231138, https://doi.org/10.5194/acp-16-1123-2016, 2016.

Yates III, L. M. and Wandruszka, R. V.: Decontamination of polluted water bytreatment with a crude humic acid blend, Environ. Sci. Technol., 33, 2076-2080, 1999.

You, Y., Renbaum-Wolff, L., and Bertram, A. K.: Liquid-liquid phase separation in particles containing organics mixed with ammonium sulfate, ammonium bisulfate, ammonium nitrate or sodium chloride, Atmos. Chem. Phys., 13, 11723-11734, https://doi.org/10.5194/acp-13-11723-2013, 2013.

Zamora, I. R., Tabazadeh, A., Golden, D. M., and Jacobson, M. Z.: Hygroscopic growth of common organic aerosol solutes, including humic substances, as derived from water activity measurements, J. Geophys. Res., 116, D23207, https://doi.org/10.1029/2011JD016067, 2011.

Zardini, A. A., Sjogren, S., Marcolli, C., Krieger, U. K., Gysel, M., Weingartner, E., Baltensperger, U., and Peter, T.: A combined particle trap/HTDMA hygroscopicity study of mixed inorganic/organic aerosol particles, Atmos. Chem. Phys., 8, 55895601, https://doi.org/10.5194/acp-8-5589-2008, 2008.
Zawadowicz, M. A., Proud, S. R., Seppalainen, S. S., and Cziczo, D. J.: Hygroscopic and phase separation properties of ammonium sulfate/organics/water ternary solutions, Atmos. Chem. Phys., 15, 8975-8986, https://doi.org/10.5194/acp-158975-2015, 2015.

Zhang, S. L., Ma, N., Kecorius, S., Wang, P. C., Hu, M., Wang, Z. B., Größ, J., Wu, Z. J., and Wiedensohler, A.: Mixing state of atmospheric particles over the North China Plain, Atmos. Environ., 125, 152-164, 2016.

Zhang, Q., Jimenez, J. L., Canagaratna, M. R., Allan, J. D., Coe, H., Ulbrich, I., Alfarra, M. R., Takami, A., Middlebrook, A. M., Sun, Y. L., Dzepina, K., Dunlea, E., Docherty, K., DeCarlo, P. F., Salcedo, D., Onasch, T., Jayne, J. T., Miyoshi, T., Shimono, A., Hatakeyama, S., Takegawa, N., Kondo, Y., Schneider, J., Drewnick, F., Borrmann, S., Weimer, S., Demerjian, K., Williams, P., Bower, K., Bahreini, R., Cottrell, L., Griffin, R. J., Rautiainen, J., Sun, J. Y., Zhang, Y. M., and Worsnop, D. R.: Ubiquity and dominance of oxygenated species in organic aerosols in anthropogenically-influenced Northern Hemisphere midlatitudes, Geophys. Res. Lett., 34, L13801, https://doi.org/10.1029/2007GL029979, 2007.

Zhong, M. and Jang, M.: Dynamic light absorption of biomass-burning organic carbon photochemically aged under natural sunlight, Atmos. Chem. Phys., 14, 1517-1525, https://doi.org/10.5194/acp-14-1517-2014, 2014.

Zuend, A. and Seinfeld, J. H.: Modeling the gas-particle partitioning of secondary organic aerosol: the importance of liquidliquid phase separation, Atmos. Chem. Phys., 12, 3857-3882, https://doi.org/10.5194/acp-12-3857-2012, 2012.

Zuend, A., Marcolli, C., Luo, B. P., and Peter, T.: A thermodynamic model of mixed organic-inorganic aerosols to predict activity coefficients, Atmos. Chem. Phys., 8, 4559-4593, https://doi.org/10.5194/acp-8-4559-2008, 2008.

Zuend, A., Marcolli, C., Peter, T., and Seinfeld, J. H.: Computation of liquid-liquid equilibria and phase stabilities: implications for RH-dependent gas/particle partitioning of organicinorganic aerosols, Atmos. Chem. Phys., 10, 7795-7820, https://doi.org/10.5194/acp-10-7795-2010, 2010.

Zuend, A., Marcolli, C., Booth, A. M., Lienhard, D. M., Soonsin, V., Krieger, U. K., Topping, D. O., McFiggans, G., Peter, T., and Seinfeld, J. H.: New and extended parameterization of the thermodynamic model AIOMFAC: calculation of activity coefficients for organic-inorganic mixtures containing carboxyl, hydroxyl, carbonyl, ether, ester, alkenyl, alkyl, and aromatic functional groups, Atmos. Chem. Phys., 11, 9155-9206, https://doi.org/10.5194/acp-11-9155-2011, 2011. 